\title{
In Situ Visualization of Protein Interactions in Sensory Neurons: Glutamic Acid-Rich Proteins (GARPs) Play Differential Roles for Photoreceptor Outer Segment Scaffolding
}

\author{
Linda M. Ritter, ${ }^{1}$ Nidhi Khattree, ${ }^{1}$ Beatrice Tam, ${ }^{2}$ Orson L. Moritz, ${ }^{2}$ Frank Schmitz, ${ }^{3}$ and Andrew F. X. Goldberg ${ }^{1}$ \\ ${ }^{1}$ Eye Research Institute, Oakland University, Rochester, Michigan 48309, ${ }^{2}$ Department of Ophthalmology and Visual Sciences, University of British \\ Columbia, Vancouver, British Columbia V5Z 3N9, Canada, and ${ }^{3}$ Department of Neuroanatomy, Institute of Anatomy and Cell Biology, Saarland University \\ Medical School, 66421 Homburg/Saar, Germany
}

\begin{abstract}
Vertebrate photoreceptors initiate vision via a G-protein-mediated signaling cascade organized within a specialized cilium, the outer segment (OS). The membranous "stacked pancake" architecture of this organelle must be partially renewed daily to maintain cell function and viability; however, neither its static structure nor renewal process is well described in molecular terms. Glutamic acid-rich proteins (GARPs), including the cyclic nucleotide-gated cation channel (CNGB1) and GARP2 (a CNGB1 splice-variant), are proposed to contribute to OS organization in concert with peripherin/rds $(\mathrm{P} / \mathrm{rds})$, a retinal tetraspanin. We developed and applied an in situ fluorescence complementation approach that offers an unprecedented glimpse at the formation, trafficking, and localization of GARP-P/rds interactions in transgenic Xenopus laevis rod photoreceptors. Interactions for these (and other) proteins could be readily visualized using confocal microscopy. Nearly all associations, including CNGB1-P/rds interaction, were initiated within inner segments (ISs) before trafficking to OSs. In contrast, GARP2-P/rds interactions were only observed downstream, at or near sites of disk morphogenesis. These results suggest that GARP2-P/rds interaction participates directly in structuring disk stacks but CNGB1-P/rds interaction does not and instead serves mainly to localize plasma membrane ion channels. Altogether, the results lead us to propose that differential interaction of GARPs with P/rds may contribute to the broad phenotypic heterogeneity produced by inherited defects in P/rds. Analogous experiments applied to the synaptic protein RIBEYE suggest that monomers can oligomerize at the level of the IS before ribbon assembly and demonstrate the general applicability of this strategy for in situ analysis of protein interactions in sensory neurons.
\end{abstract}

\section{Introduction}

Rod and cone photoreceptors are highly polarized sensory neurons essential for vertebrate vision (Burns and Arshavsky, 2005). Their light responses are mediated by specialized cilia, commonly known as outer segments (OSs). These elaborate structures contain hundreds of membranous disks stacked one on top of another and enclosed (partially as in cones, or fully as in rods) by a plasma membrane (PM). OSs are partially renewed on a daily

\footnotetext{
Received June 8, 2011; accepted June 11, 2011.

Author contributions: L.M.R., 0.L.M., and A.F.X.G. designed research; L.M.R., N.K., B.T., and A.F.X.G. performed research; L.M.R., N.K., B.T., O.L.M., F.S., and A.F.X.G. analyzed data; L.M.R., O.L.M., F.S., and A.F.X.G. wrote the paper.

Funding for this work was provided to A.F.X.G. by the National Institutes of Health (NEl award EY013246 and NCRR award RR017890) and the E. Matilda Zeigler Foundation, to 0.L.M. by the Canadian Institutes of Health Research, and to F.S. by a grant (SFB894) from the German Research Community (DFG). We appreciate generous reagent contributions by: Dr. Steven Michnick (Venus CDNA), Dr. Robert S. Molday (CNGB1 CDNA), Dr. Daniel Oprian (opsin CDNA), Dr. David Papermaster (transgenic xrds38-GFP X. laevis animals), and Dr. Clay Smith (anti-rhodopsin monoclonal antibody K62-82). Monoclonal antibodies $12 \mathrm{G} 10$ and $9 \mathrm{E} 10$ were obtained from the Developmental Studies Hybridoma Bank, University of lowa. Valuable technical assistance was provided by Loan Dang (Oakland University) and Christopher Edwards (University of Michigan).

The authors declare no competing financial interests.

Correspondence should be addressed to Andrew F. X. Goldberg, Eye Research Institute, 417 DHE, Oakland University, Rochester, MI 48309. E-mail: goldberg@oakland.edu.

DOI:10.1523/JNEUROSCI.2875-11.2011

Copyright $\odot 2011$ the authors $\quad 0270-6474 / 11 / 3111231-13 \$ 15.00 / 0$
}

basis by a coordinated process of disk growth and shedding (Bok and Young, 1972). This process is required to maintain cell function and viability; defects produce a variety of retinal dystrophies in humans (Berger et al., 2010). The mechanisms by which materials are sorted into specialized membrane domains, assemble into mature disks, and transit toward eventual shedding remain to be defined. These questions have received broader attention, as it has become clear that ciliopathies contribute to a wide range of human diseases (Fliegauf et al., 2007; Ramamurthy and Cayouette, 2009; Sung and Chuang, 2010).

Static OS structure has been well described at the light and electron microscopic levels (Kennedy and Malicki, 2009) but remains to be elucidated at the molecular level. The membranous disks that distinguish this organelle possess flattened central lamellae and highly curved rim regions at their peripheries. A molecular scaffolding has been proposed to underlie disk rim and incisure morphology (Corless and Fetter, 1987), potentially supporting a matrix of SEM-visualized filaments that bridge adjacent disk rims (Roof and Heuser, 1982; Kajimura et al., 2000). Filaments have not been identified at the protein level and the model remains speculative; however, a series of alternatively spliced glutamic acid rich protein (GARP) variants (Colville and Molday, 
1996) and peripherin/rds (P/rds), an integral membrane tetraspanin (Molday et al., 1987; Connell et al., 1991; Travis et al., 1992), have been proposed to function as participants (Goldberg, 2006; Zhang et al., 2009). Alternative proposals suggest that GARPs mediate "transdusosome" formation at disk rims, which include phototransduction cascade proteins but exclude $\mathrm{P} / \mathrm{rds}$ (Körschen et al., 1999), and that disk stacks are maintained by widely distributed rather than rim-localized complexes (Nickell et al., 2007).

As a first step toward elucidating how protein-protein interactions contribute to OS disk structure and renewal in situ, we have developed a bimolecular fluorescence complementation (BiFC) method for use in intact vertebrate photoreceptors, and applied it to visualize homotypic and heterotypic protein interactions crucial for cell structure and function. Although $\mathrm{P} / \mathrm{rds}$ forms a protein complex with a homolog, rom-1, in mammalian species, the latter plays a nonessential regulatory role (Clarke et al., 2000) and therefore was not treated here. In sum, the current results demonstrate that OS and synaptic proteins commonly oligomerize at the biosynthetic level, GARPs interactions are splice variant specific, and assembly of GARP2 with P/rds may occur in concert with disk morphogenesis. These findings advance understanding of mechanisms underlying assembly of OS and synaptic structures and provide a tractable approach for investigating protein interactions and trafficking in native cellular environments.

\section{Materials and Methods}

Fusion protein constructs for expression in cultured cells and Xenopus laevis. Standard recombinant DNA techniques were used to fuse coding sequences for bovine orthologs of P/rds, CNGB1, GARP2, and RHO and the rat RIBEYE (B) domain, both upstream and (in most instances) downstream of nonfluorescent fragments of enhanced green fluorescent protein (eGFP) and/or Venus (Nagai et al., 2002). Nonfluorescent fragments ( $\mathrm{N}$ terminus, amino acids $1-158$; $\mathrm{C}$ terminus, amino acids $159-$ 239) of eGFP and Venus, previously shown capable of reconstituting mature fluorophores (Michnick et al., 2010), were fused to proteins of interest using a nine amino acid (GGSGASGGS) flexible linker encoding a NarI restriction site. To abrogate potential for weak dimerization, an alanine-to-lysine missense mutation was introduced into the C-terminal fragment of Venus at position 206 (Zacharias et al., 2002) using a QuikChange II XL Site-Directed Mutagenesis Kit (Stratagene). A series of epitope-tagged expression constructs was created by subcloning individual HA (YPYDVPDYA) and c-myc tags (EQKLISEEDL) into NarI sites. Kozak translation initiation and stop codon sites were incorporated as required for proper eukaryotic expression. DNA sequences were verified using BigDye terminator cycle sequencing (Applied Biosystems). Full-length constructs were subcloned into vectors suitable for expression in cultured cells [pcDNAI/AMP or pcDNA3 (Invitrogen) and $X$. laevis rod photoreceptors (XOP0.8-eGFPN1) (Tam et al., 2006)].

Protein expression and analysis in cultured mammalian cells. HEK293 or AD293 cells (Stratagene) were transiently transfected with FuGENE 6 (Roche Diagnostics), essentially as recommended by the manufacturer. For Western analysis, cells were scraped from $100 \mathrm{~mm}$ dishes $48 \mathrm{~h}$ posttransfection, and stored as pellets at $-20^{\circ} \mathrm{C}$. SDS-PAGE and Western blotting were performed as described previously (Goldberg et al., 2007). For immunocytochemical (ICC) analysis, cells grown in chamber slides were fixed with $4 \%$ paraformaldehyde and permeabilized/blocked with $0.2 \%$ Triton X-100, 10\% goat serum in PBS. Cells were labeled sequentially with anti-HA rat monoclonal antibody (Mab) 3F10 (Roche) and Alexa Fluor 568 anti-rat IgG (Invitrogen) and then with anti-myc mouse Mab 9E10 (Developmental Studies Hybridoma Bank, University of Iowa, Iowa City, Iowa) and Alexa Fluor 647 anti-mouse IgG (Invitrogen).

Protein expression and analysis in transgenic X. laevis. Transgenic tadpoles were generated using a modified restriction enzyme-mediated integration (REMI) method (Moritz et al., 1999) and complementary BiFC plasmids linearized with FseI. Purified plasmids were combined at a ratio of $200 \mathrm{ng}$ total DNA to $\sim 4 \times 10^{5}$ sperm nuclei before injection. Viable embryos were reared at $18^{\circ} \mathrm{C}$ on a 12:12 light cycle; embryos were selected with G418 in some instances as described previously (Moritz et al., 2002). At 5-7 d postfertilization (dpf) and again at 10-12 dpf, tadpoles were screened for ocular fluorescence using a Zeiss Axioskop or Nikon Optiphot-2 microscope equipped with an epifluorescence illuminator and GFP filter set. Tadpoles (14-16 dpf) were sacrificed for analysis by Tricaine overdose and pithing, and eyes were enucleated.

For BiFC and immunohistochemical (IHC) analyses, eyes were fixed overnight in $4 \%$ paraformaldehyde at $4^{\circ} \mathrm{C}$, cryoprotected in sucrose, then frozen in OCT. OCT cryosections $(12 \mu \mathrm{m})$ from at least three animals were processed for analysis. As described for REMI transgenesis in the $X$. laevis system previously (Moritz et al., 2001), transgenic protein expression levels varied in different animals, in different cells within the same animal, and over time within single cells. Thus, it was possible to survey several primary transgenic animals and numerous cells within each animal to identify the contributions to localization made by a given fusion protein pair. Immunoreagents included the following: anti-GFP rabbit Pab290 (Abcam), anti-HA rabbit Pab9110 (Abcam), anti-myc mouse Mab 9E10 (Developmental Studies Hybridoma Bank), anti-frog P/rds (xrds38) mouse Mab 1G9 (custom generated), anti-bovine P/rds mouse Mab C6 (Goldberg et al., 2001), anti-calnexin rabbit SPA-865 (Enzo Life Sciences), anti-rabbit IgG Alexa Fluor568 conjugate (Invitrogen), antimouse IgG Alexa Fluor 647 conjugate (Invitrogen), and a wheat germ agglutinin (WGA) Alexa Fluor 647 conjugate (Invitrogen). Images were acquired using a Zeiss510-Meta or Nikon C1 LSCM with $60 \times$ and $63 \times$ water-immersion objectives. To minimize potential for overexpressioninduced mislocalization and/or structural defects, fields containing the best oriented and contiguous photoreceptors showing modest transgenic protein expression were imaged. Laser power was minimized to diminish photobleaching, photomultiplier voltages were adjusted to avoid pixel saturation, and a confocal aperture of $60 \mu \mathrm{m}$ was used unless otherwise noted. Brightness/contrast (Deneba Canvas) or lookup tables (Nikon Elements) were adjusted to optimize feature visualization in some instances; careful comparisons with original files were conducted to ensure that no significant qualitative changes were introduced into fluorescence distributions.

For immunogold ultrastructural analysis, eyes from at least two animals were fixed at room temperature for $4 \mathrm{~h}$ in $4 \%$ paraformaldehyde containing $0.1 \%$ glutaraldehyde, then dehydrated through a graded ethanol series, and embedded in LR White resin. Thin sections cut from LR White embedded eyes were processed for postembedding immunogold labeling with primary antibodies, gold-conjugated secondary antibodies, and silver enhancement, essentially as described previously (Goldberg et al., 2007). Grids were stained with uranyl acetate and lead citrate and imaged in an FEI Morgagni transmission electron microscope at $80 \mathrm{kV}$.

For Western analysis, isolated eyes were solubilized in Laemmli sample buffer with boiling for $10 \mathrm{~min}$ and loaded onto polyacrylamide mini-gels at $\sim 1.5$ eyes/lane. Proteins were transferred to Immobilon-FL PVDF (Millipore) and blots were developed using anti-GFP rabbit Pab290 (1: 3000, Abcam) and anti- $\alpha$ tubulin mouse Mab 12G10 (1:3000, Developmental Studies Hybridoma Bank) primary antibodies, followed by goat anti-rabbit IgG coupled to IR Dye680 and goat anti-mouse IgG coupled to IR Dye800CW (1:10,000, LI-COR) secondary antibodies. Blots were analyzed using the Odyssey Infrared Imaging System (LI-COR).

Immunoprecipitation analyses were conducted using anti-xP/rds Mab 1G9 covalently coupled to Sepharose beads at $\sim 5 \mathrm{mg}$ of purified IgG per milliliter of beads (CNBr-activated Sepharose 4B, GE Healthcare) and anti-GFP magnetic beads (Allele Biotech). Proteins from 10 tadpole eyes were solubilized in the presence of a protease inhibitor cocktail (Roche Diagnostics) using $25 \mu \mathrm{l}$ of $1 \%$ Triton X-100 in PBS, pH 7.5, for 30 min on ice, with gentle vortexing. The solution was diluted sevenfold with PBS and then centrifuged $30,000 \times g$ for $30 \mathrm{~min}$ at $4^{\circ} \mathrm{C}$, and the clarified extract was incubated with immunoaffinity matrix $(\sim 15 \mu \mathrm{l}$ bead volume) for $1 \mathrm{~h}$ with gentle agitation at room temperature. After collection of the unbound fraction, beads were washed with 12 volumes of $0.1 \%$ Triton X-100 in PBS, and bound proteins were eluted in Laemmli sample buffer by heating $\left(95^{\circ} \mathrm{C}\right)$ for $10 \mathrm{~min}$. Fractions were analyzed by Western 
blotting using the procedures detailed above and the following primary antibodies: anti-frog P/rds (xrds38) PabFCT (1:1000; custom generated), antiGFP Pab290 (1:3000; Abcam), anti-HA Pab9110 (1:500; Abcam), anti-myc Mab 9E10 (1:500; Developmental Studies Hybridoma Bank), and antirhodopsin K62-82 (1:100; a kind gift from Dr. Clay Smith, University of Florida, Gainesville, FL).

\section{Results}

The BiFC assay implemented here uses the documented tendency of two complementary and nonfluorescent fragments of GFP to reconstitute a mature fluorophore when brought into close apposition (Ghosh et al., 2000; Magliery et al., 2005). Genetic fusion of the GFP fragments to individual partners of interest creates a reporter system for protein interaction (Fig. $1 A$ ). This approach offers several advantages important for our purposes, including high sensitivity and suitability for use with integral membrane proteins. Moreover, since BiFC complexes do not require exogenous substrates and can form in a variety of subcellular compartments, this strategy allows direct visualization of protein assembly sites in the normal cellular milieu. We reasoned that the sensitivity and versatility of this approach would allow us to apply it in transgenic $X$. laevis to investigate protein assembly processes proposed to scaffold retinal photoreceptors.

\section{Visualization of photoreceptor protein interactions in cultured cells by BiFC}

We used heterologous expression in HEK293 cells to determine whether photoreceptor proteins fused to fragments of GFP could drive BiFC complex formation and applied the analysis to $\mathrm{P} / \mathrm{rds}$, GARP2, and rhodopsin, each of which is reported to self-associate. Figure $1 B$ shows fusion protein designs incorporating epitope tags; these constructs allow independent identification of each fusion protein partner in cotransfected cells. The total transgenic protein present was identified using an anti-GFP polyclonal serum that reacted with each fragment (GFPa and GFPb).

Pairs of plasmids encoding complementary fusion protein partners were transiently cotransfected into cells, and lysates were analyzed by Western blotting using anti-GFP, anti-HA, and antimyc antibodies. We found that all constructs were expressible in the heterologous system (Fig. $1 C$ ). The results shown in Figure $1 \mathrm{D}$ demonstrate that all eight fusion proteins were detectable by ICC epitope tag analysis of fixed and permeabilized cells. However, of the three proteins tested, only cells cotransfected with plasmids encoding $\mathrm{P} / \mathrm{rd}$ s fused to complementary GFP fragments showed significant BiFC complex formation (green), regardless of whether fusions were made at the $\mathrm{N}$ or $\mathrm{C}$ termini. Although both rhodopsin and GARP2 have been reported to self-associate (Fotiadis et al., 2004; Batra-Safferling et al., 2006), neither generated significant BiFC signal.

We subsequently tested whether a more stable and robustly fluorescent GFP variant, Venus (Nagai et al., 2002), could provide additional sensitivity for more weakly interacting proteins. We created a series of Venus-based constructs analogous to those already described for GFP and incorporated a A206K mutation into the $\mathrm{Vb}$ fragment to eliminate the weak dimerization characteristic of GFP-derived proteins (Zacharias et al., 2002). Epitope tags were also included in these constructs to allow for IHC localization of individual fusion proteins. As expected, cells cotransfected with complementary plasmids encoding $\mathrm{P} / \mathrm{rds}$ Venus fusion proteins produced substantial BiFC fluorescence (data not shown). Furthermore, Venus fusions evidenced increased sensitivity, as weak BiFC signals were also observed for homotypic associations of both rhodopsin and GARP2 (Fig. 2A).
The Venus-based BiFC assay also proved capable of detecting heterotypic interactions (Fig. 2B). Cotransfections of GARP2 and $\mathrm{P} / \mathrm{rds}$ constructs produced significant $\mathrm{BiFC}$ signal, confirming a previously reported interaction between GARP2 and P/rds (Poetsch et al., 2001). Reconstitution of this association in a kidney cell line demonstrates that it does not require the presence of other photoreceptor-specific proteins. Coexpression of proteins not thought to associate (GARP2 and rhodopsin) did not generate significant BiFC, suggesting that specific protein-protein interaction was required to drive Venus maturation in the cultured cells.

\section{Peripherin/rds self-assembly visualized via a BiFC assay in photoreceptors}

We next asked whether the BiFC strategy could be applied to the visualization of protein complexes in adult vertebrate photoreceptors. Restriction enzyme-mediated integration, REMI was used to generate transgenic $X$. laevis for this purpose, since previous studies have shown the utility of this system for investigating GFP-tagged photoreceptor proteins (Knox et al., 1998; Moritz et al., 1999, 2001). Proof of principle was evaluated using self-association of $\mathrm{P} / \mathrm{rds}$ as a positive control. $\mathrm{N}$ - and C-terminal GFP fragments individually fused to bovine $\mathrm{P} / \mathrm{rds} \mathrm{cDNAs}$ (referenced as $\mathrm{bP} / \mathrm{rds}-\mathrm{GFPa}$ and $\mathrm{bP} / \mathrm{rds}-\mathrm{GFPb}$, respectively) were placed under control of a X. laevis opsin promoter (Knox et al., 1998) and used individually and in combination to generate transgenic $X$. laevis by REMI. Epitope tags were not included in these constructs to simplify interpretation.

Transgenic animals were identified by ocular fluorescence imaged in vivo. Figure $3 \mathrm{~A}$ shows examples of in vivo epifluorescent (insets) and confocal (fixed cryosection) images from a nontransgenic tadpole and a $14 \mathrm{dpf}$ tadpole derived from a transgenic line expressing the $X$. laevis $\mathrm{P} / \mathrm{rds}$ ortholog $(x r d s 38)$ fused to fulllength GFP under the control of an opsin promoter (Loewen et al., 2003). These cryosections were labeled with WGA (red) and Hoechst dye (blue) to identify OSs and nuclei. The transgenic fusion protein $\mathrm{xP} / \mathrm{rds}-\mathrm{GFP}$ was observed in OSs of numerous photoreceptors in this section. Figure $3 B$ shows a Western blot that compares expression of $\mathrm{xP} / \mathrm{rds}-\mathrm{GFP}, \mathrm{bP} / \mathrm{rds}-\mathrm{GFPa}$ alone, and $\mathrm{bP} / \mathrm{rds}-\mathrm{GFPa}+\mathrm{bP} / \mathrm{rds}-\mathrm{GFPb}$ in eye lysates from transgenic tadpoles at $14 \mathrm{dpf}$. Fusion proteins, as assayed by Western blotting, were expressed with mobilities consistent with their predicted molecular weights (MWs). Doublet bands were commonly observed for each fusion protein, likely a function of heterologous glycosylation of $\mathrm{P} / \mathrm{rds}$. When expressed alone, bP/ rds-GFPa was susceptible to proteolytic degradation, perhaps due to instability of the N-terminal GFP fragment at its $\mathrm{C}$ terminus. Coexpression of $\mathrm{bP} / \mathrm{rds}-\mathrm{GFPb}$ protected against this effect, as would be expected for complementation producing properly folded and complete GFP.

Cryosections from $14 \mathrm{dpf}$ transgenic tadpole eyes were labeled with WGA (white), Hoechst dye (blue), and anti-GFP antisera (red) to identify OSs, nuclei, and transgenic fusion proteins, respectively. The confocal micrographs presented in Figure $3 C$ show that coexpression of the bP/rds-GFPa and bP/rds-GFPb fusion proteins generated robust BiFC. These signals were exclusively localized to rod photoreceptor cells and were typically present in relatively few cells (typically 6-12) of a given section, a result consistent with the mosaic expression reported previously for transgenic X. laevis retina (Moritz et al., 2001). Interestingly, substantial BiFC was commonly observed in both inner segments (ISs) and OSs. Since photoreceptor OS proteins are synthesized in ISs, these findings suggest that the initial step of P/rds self- 
assembly occurs at the biosynthetic level, a result consistent with $\mathrm{P} / \mathrm{rds}$ assembly in cultured cells (Goldberg et al., 1995). BiFC signals largely overlapped transgenic protein distribution (as revealed by antiGFP IHC); this result suggests that fusion proteins expressed in these cells were efficiently incorporated into complexes. BiFC signal distributions were somewhat heterogeneous between individual cells (for an example, see Fig. 4). High-level expression tended to disrupt OS structure, particularly OSs in older (central) photoreceptors, as they appeared shorter, thinner, and more dysmorphic than those in the periphery. In contrast, when we generated transgenic animals using the $\mathrm{bP} /$ rds-GFPa construct alone, no BiFC signals were observed, and OS structure appeared normal. The individually expressed protein did show robust retinal expression that was completely localized to rod photoreceptor cells and largely restricted to OSs. This distribution mirrored that of transgenic $\mathrm{xP} / \mathrm{rds}$ fused to full-length GFP. In sum, the results demonstrate that the $\mathrm{BiFC}$ assay can be used to visualize integral membrane protein self-association in adult vertebrate photoreceptors. Furthermore, the presence of significant signal within photoreceptor ISs (as well as OSs) suggests an initial interaction at the biosynthetic level and slowed trafficking of BiFC complexes to OSs.

To further refine transgenic protein distribution, a postembedding immunogold labeling analysis was performed to localize transgenic proteins at the ultrastructural level. Figure $3 D$ shows transmission electron micrographs that compare distributions of the following: (1) transgenically coexpressed bP/rds-GFPa + $\mathrm{bP} / \mathrm{rds}-\mathrm{GFPb}$ (detected with Pab290); (2) transgenically expressed $\mathrm{xP} /$ rds-GFP (detected with Pab290); and (3) endogenous $\mathrm{P} / \mathrm{rds}$ (detected with Mab 1G9). In each case, gold particles were observed primarily in OSs and were largely distributed alongside plasma membranes and disk incisures-patterns consistent with disk rim localization. Since the OS distributions of both the fragmented and full-length GFP fusion proteins largely mirrored those of endogenous $\mathrm{P} / \mathrm{rds}$, we conclude that neither genetic fusion nor fluorophore formation prevented normal localization of the $\mathrm{P} / \mathrm{rds}$ fusion proteins. Gold particles were also observed in some ISs of the bP/rds-GFPa + $\mathrm{bP} / \mathrm{rds}-\mathrm{GFPb}$ cotransgenics, particularly in highly expressing cells (compare Fig. $3 E$, right and left). There results are consistent with distributions noted in our IHC analyses. Labeling was not observed in other cell
A
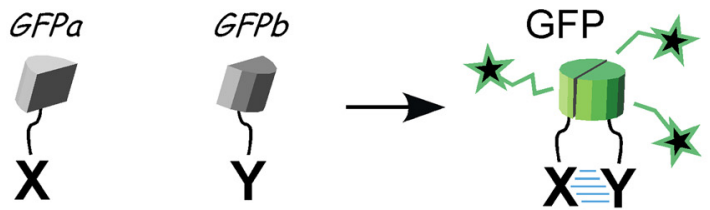

B

\begin{tabular}{|c|c|c|}
\hline P/rds & HA & GFPa \\
\hline \hline P/rds & MYC & GFPb \\
\hline
\end{tabular}

\begin{tabular}{|c|c|c|}
\hline GFPa & HA & P/rds \\
\hline \hline GFPb & MYC & P/rds \\
\cline { 3 - 4 } & &
\end{tabular}

\begin{tabular}{|l|l|l|}
\hline RHO & HA & GFPa \\
\hline \hline RHO & MYC & GFPb \\
\hline \multicolumn{2}{|c|}{} \\
\hline GARP2 & HA & GFPa \\
\hline GARP2 & MYC & GFPb \\
\hline
\end{tabular}
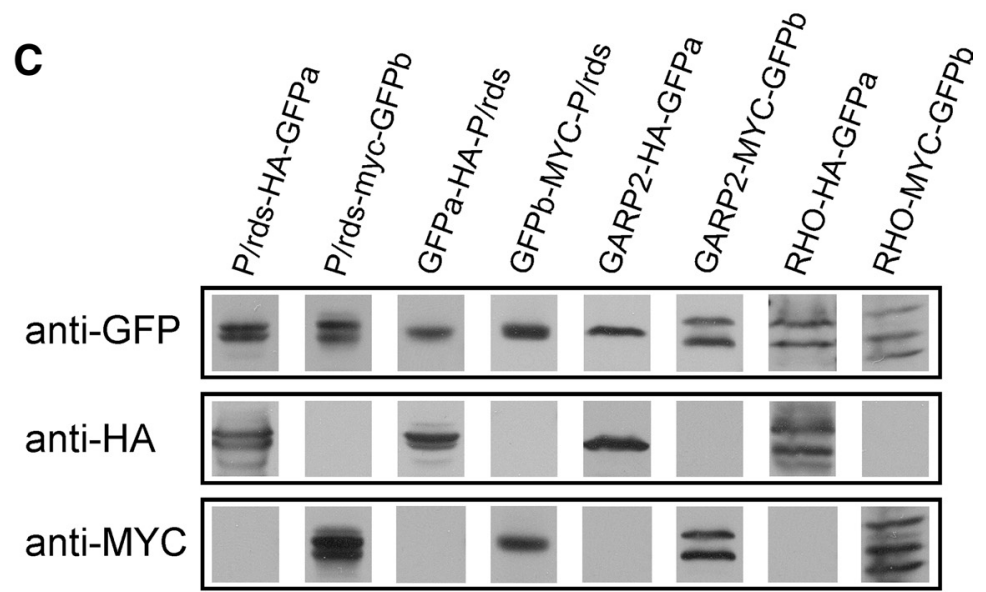

D

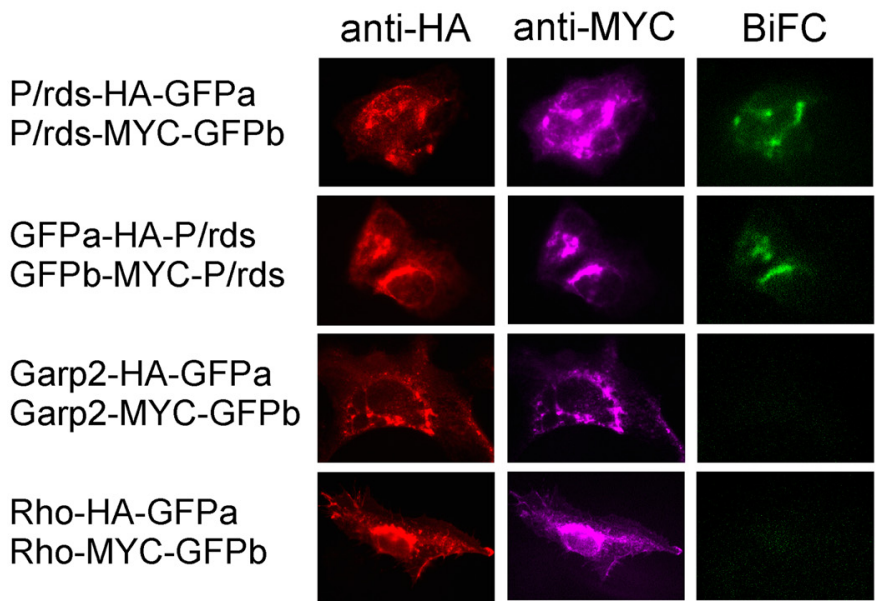

Figure 1. A GFP-based BiFC assay reports photoreceptor protein interactions in cultured cells. $\boldsymbol{A}$, The approach uses fusions of nonfluorescent $\mathrm{N}$ - and C-terminal fragments of GFP (or YFP, yellow fluorescent protein) to partners of interest. Interaction of the partners ( $\mathbf{X}, \mathbf{Y})$ brings the complementary fragments into proximity, promoting fluorophore maturation. $\boldsymbol{B}$, GFP fragment fusion protein variants encoding photoreceptor proteins - P/rds, rhodopsin, and GARP2. $\boldsymbol{C}$, Western blot analysis of fusion protein expression in transiently transfected HEK293 cells. The results demonstrate that all constructs can be expressed and that the epitope tag antibodies react specifically. $\boldsymbol{D}$, Coexpression of complementary (GFPa and GFPb) fragments fused to either the $\mathrm{N}$ or $\mathrm{C}$ terminus of $\mathrm{P} / \mathrm{rds}$ produced relatively modest BiFC signals (green) imaged by widefield epifluorescence microscopy. IHC analysis of the individual partners (HA, red; MYC, fuchsia) shows them to be overlapping with, but more broadly distributed than the BiFC signals. A similar assay applied to GARP2 and rhodopsin produced no significant signals, although previous reports suggest that each may engage in weak self-association (Batra-Safferling et al., 2006; Fotiadis et al., 2004). In sum, these results suggest that a BiFC assay based on GFP fragments is sufficient to detect strong, but not weak, interactions. 
A

Garp2-HA-Va Garp2-MYC-Vb

Va-HA-Garp2 Vb-MYC-Garp2

Rho-HA-Va
Rho-myc-Vb

B

Va-HA-Garp2
P/rds-MYC-Vb

Va-HA-Garp2 Rho-MYC-Vb

Va-HA-Garp2 Vb-MYC-P/rds HA peptide

Va-HA-Garp2
Vb-myc-P/rds
MYC peptide

Va-HA-Garp2 Vb-MYC-P/rds
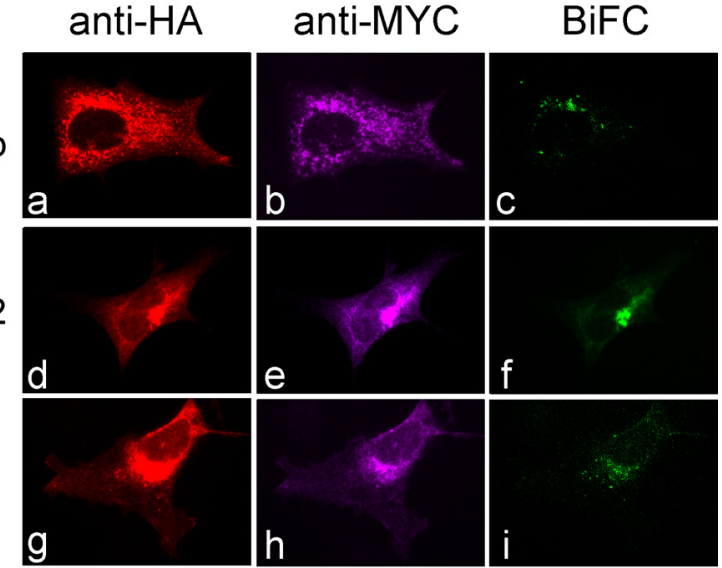

g

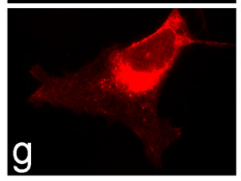

$$
\text { anti-HA }
$$

anti-MYC
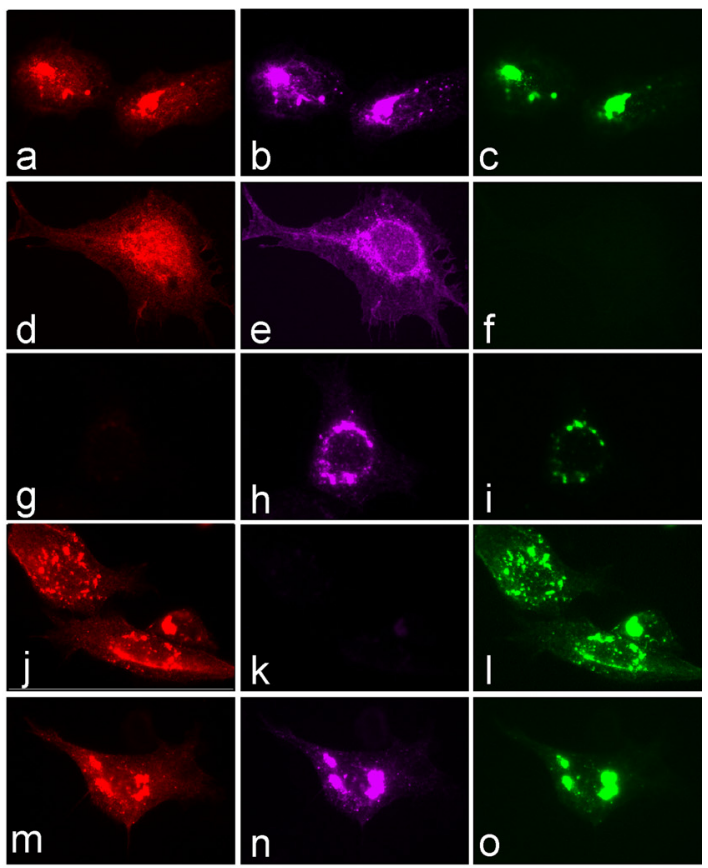

Garp2-HA-Va P/rds-MYC-Vb

Garp2-HA-Va Vb-MYC-P/rds
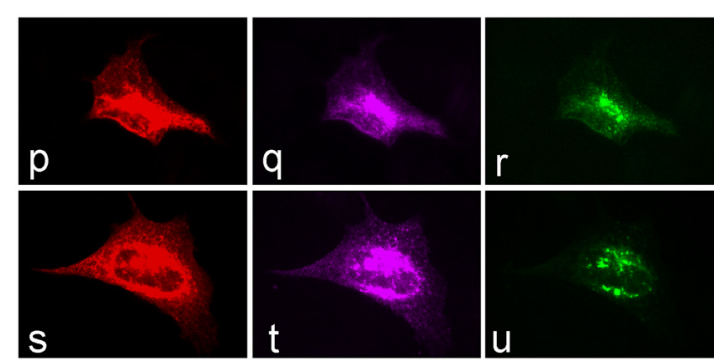

Garp2-HA-Va Rho-MYC-Vb
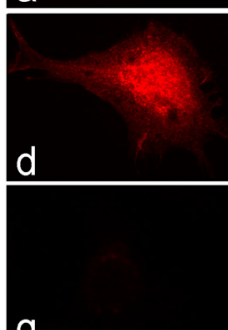
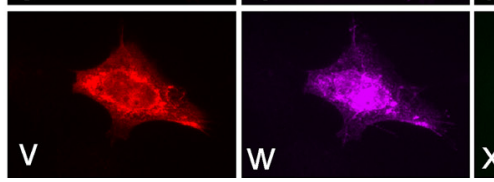

types, including cone photoreceptors (Fig. $3 E$, left; COS, cone outer segment), as expected for expression driven by a rod opsin promoter. The coexpressed GFP fragment$\mathrm{P} / \mathrm{rds}$ fusion proteins displayed significant presence within ISs, but the full-length GFP-P/rds fusion protein did not; thus, immunogold labeling data, like the immunofluorescence experiments, suggested that IS distributions were correlated with formation of mature BiFC complexes.

Overall, the findings presented in Figure 3 provide a proof-of-principle that BiFC can be applied in adult $X$. laevis photoreceptors to visualize protein assembly processes known to function in support of OS structure.

\section{Homotypic interactions of other} photoreceptor proteins visualized in situ

Given that the BiFC assay allowed visualization of $\mathrm{P} / \mathrm{rds}$ self-assembly, we asked whether this strategy could be generalized to monitor other self-associating proteins. Figure 4 shows the application of our approach to three additional examples. CNGB1 is an ion channel protein subunit well documented to oligomerize (Zheng et al., 2002; Zhong et al., 2002), most likely within the endoplasmic reticulum (Deutsch, 2002); it is normally localized to the rod OS plasma membrane (Cook et al., 1989). Rhodopsin, the major protein of the rod OS, is also proposed to oligomerize (Fotiadis et al., 2004) and is present in both disks and plasma membrane. RIB(B), a selfassociating domain of the RIBEYE protein, is an essential oligomeric building block of photoreceptor synaptic ribbons (Schmitz et al., 2000; Magupalli et al., 2008).

Similar to GFP-based experiments (Fig. 3C), Venus BiFC signals driven by $\mathrm{P} / \mathrm{rds}$ self-association (Va-HA-P/rds + $\mathrm{Vb}-\mathrm{MYC}-\mathrm{P} / \mathrm{rds}$ ) were commonly found in both ISs and OSs (Fig. 4a). IHC labeling with Pab290 (Fig. 4b), a reagent that labeled both $\mathrm{N}$ - and C-terminal fragments of Venus, largely overlapped BiFC signals; this result suggests that a large fraction of the transgenic protein expressed was assembled into complexes.

Transgenic coexpression of Venus fusion proteins incorporating CNGB1 coding regions generated substantial $\mathrm{BiFC}$ in

Figure 2. BiFC assay based on Venus, a highly fluorescent YFP (yellow fluorescent protein) variant (Nagai et al., 2002), allows detection of additional homotypic interactions by widefield epifluorescence microscopy. $A$, Coexpression of complimentary pairs of Venus-based fusion proteins generated modest BiFC signals for both GARP2 and rhodopsin, consistent with reports that these proteins can weakly self-associate. IHC analysis of the individual partners (HA, red; MYC, fuchsia) shows them to be overlapping with, but more broadly distributed than the BiFC signals (green). Self-assembly of P/rds produced robust BiFC under similar conditions (data not shown). B, BiFC assay of proposed heterotypic interactions (Poetsch et al., 2001) between GARP2 and P/rds Coexpression of Va-HA-GARP2 and P/rds-MYC-Vb partners produced a moderate BiFC signal. IHC analysis of the partners shows them to be overlapping with but more broadly distributed than the BiFC signal. In contrast, coexpression of Va-HA-GARP2 with rhodopsin (Rho-MYC-Vb) did not produce significant BiFC, despite robust expression of each partner. IHC epitope tag detection was specific, since reactivity could be blocked by synthetic peptide preincubation. All combinations of complementary GARP2-P/rds partners (such as GARP2-HA-Va and P/rdsMYC-Vb shown) were found to produce similar levels of BiFC. 
A
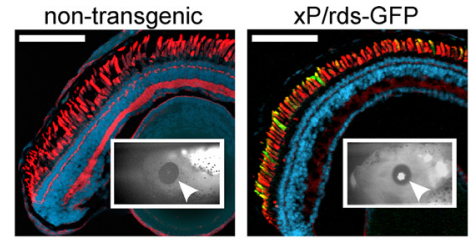

B

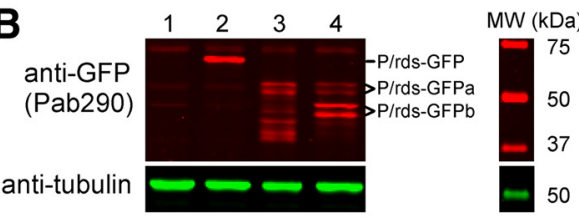

C

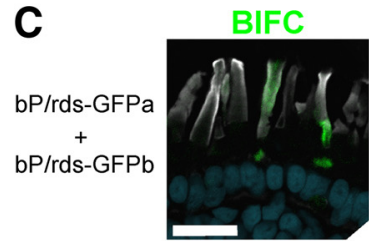
BIFC

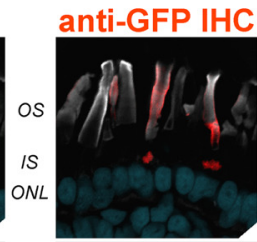

bP/rds-GFPa
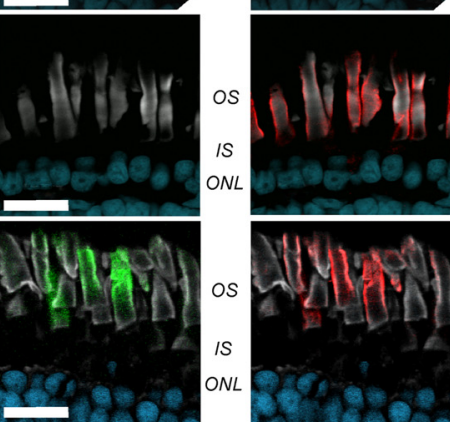

D

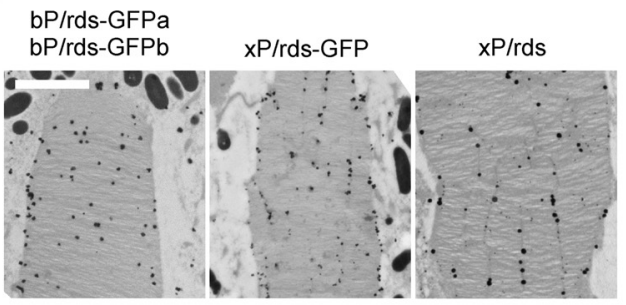

E
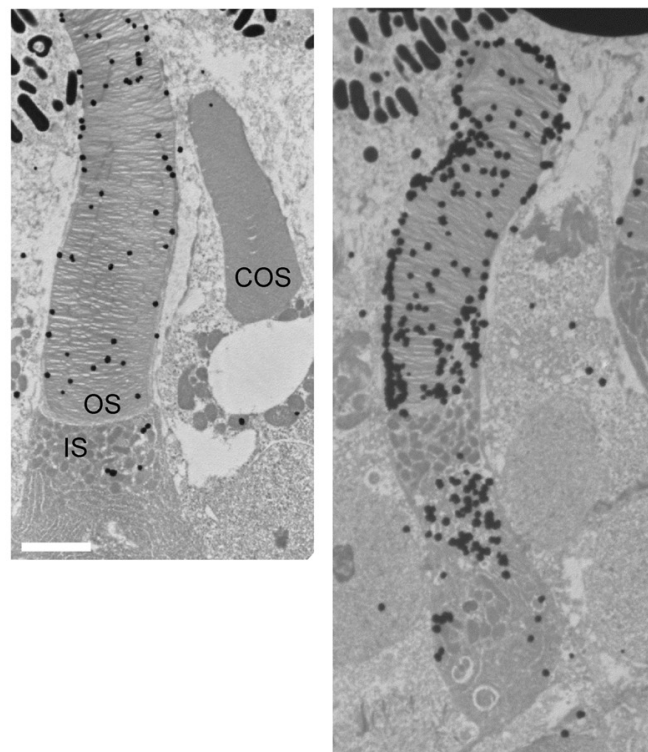

Figure 3. A GFP-based BiFC assay detects and localizes P/rds self-assembly in transgenic $X$. laevis photoreceptor cells. We predicted that P/rds tetramerization, as a model for homotypic protein-protein interaction, could drive robust BiFC in situ. $A$, Confocal micrographs of ocular cryosections from 14 dpf tadpoles showing GFP (green), WGA-labeled photoreceptor 0Ss (red), and Hoechst stained nuclei (blue). GFP fluorescence in positive control animals expressing a XP/rds-GFP fusion protein was associated solely with 0Ss. Scale bars, $100 \mu \mathrm{m}$. Insets, Transgenic tadpoles were identified in vivo via widefield epifluorescence screening; GFP was clearly visible through the lens and cornea (arrowheads). $\boldsymbol{B}$, Western blot analysis of whole eye lysates from $14 \mathrm{dpf}$ tadpoles. Lane 1, Nontransgenic control; lane 2, xP/rds-GFP (predicted $66 \mathrm{kDa}$ ); Iane 3, bP/rds-GFPa (predicted $58 \mathrm{kDa}$ ); lane 4, bP/rds-GFPa (predicted $58 \mathrm{kDa}$ ) + bP/rds-GFPb (predicted 49 kDa). The anti-GFP antisera reacted with both $\mathrm{N}$ - and C-terminal fragments of GFP (and therefore both fusion protein partners). Partners were expressed at predicted MWs as doublets, likely due to heterologous glycosylation. Proteolytic degradation of bP/rds-GFPa was alleviated by coexpression of bP/rds-GFPb. $\beta$-Tubulin reactivity was assayed as a loading control. $\boldsymbol{C}$, Confocal micrographs of ocular cryosections showing BiFC (green), WGA labeling of OSs (white), anti-GFP labeling of transgenic proteins (red), and Hoechst stained nuclei (blue); Scale bars, $20 \mu \mathrm{m}$. Coexpression of complementary partners encoding $\mathrm{N}$ - and C-terminal GFP fragments (GFPa, GFPb) individually fused to bP/rds sequences produced strong BiFC in both ISs and OSs, consistent with an initial assembly process within the IS. Expression of a single partner ( $\mathrm{bP} / \mathrm{rds}$-GFPa) did not generate BiFC. D, Distributions of transgenically expressed GFP fusion proteins in a modestly expressing OS, documented at the ultrastructural level by immunogold transmission electron microscopy (TEM) analysis; Scale bar, $2 \mu \mathrm{m}$. The bP/rds fusion proteins (detected with anti-GFP Pab290) were primarily localized at disk rims and incisures; occasional lamellar reactivity was observed. Similar results were seen for XP/rds-GFP transgenic expression, as reported previously (Loewen et al., 2003). These patterns are also similar to that previously reported for endogenous X. laevis P/rds (Kedzierski et al., 1996), detected here with Mab 1G9. E, Wider-view fields showing transgenically expressed bP/rds-GFPa + bP/rds-GFPb fusion proteins in modestly (left) and highly (right) expressing cells. Immunogold TEM analysis used anti-GFP Pab290 for labeling the transgenic proteins. COS, Cone outer segment. Scale bar, $2 \mu \mathrm{m}$.

rod photoreceptors (Fig. 4c) when Venus fragments were fused at channel N termini (Va-HA-CNGB1 + Vb-MYC-CNGB1). Akin to distributions generated by $\mathrm{P} / \mathrm{rd}$ s oligomerization, $\mathrm{BiFC}$ signals driven by homotypic CNGB1 interactions were typically observed both in ISs and OSs, as expected for channel subunit assembly at the biosynthetic level. IS distributions were most commonly observed as focal puncta (Fig. $4 c$, arrowhead), while OS fluorescence patterns were consistent with localization to the plasma membrane. Interestingly, $\mathrm{BiFC}$ signals were also frequently observed in the OPL, indicating localization within synaptic termini. Overall, we found that BiFC signals and distributions of transgenic protein largely coincided (compare Fig. $4, c, d$ ). In contrast to results for P/rds, CNGB1 self-assembly produced BiFC only when Venus fragments were fused at $\mathrm{N}$ termini but not $\mathrm{C}$ termini (data not shown). We found this result intriguing because a recent report suggests the CNGB1 C terminus may be engaged by ankyrin-G (Kizhatil et al., 2009).

When Venus fragments were fused to rhodopsin, coexpression of the transgenic fusion proteins ( $\mathrm{RHO}-\mathrm{HA}-\mathrm{Va}+\mathrm{RHO}-\mathrm{MYC}-\mathrm{Vb}$ ) generated substantial levels of BiFC in rod photoreceptors (Fig. 4 e). The N-terminal domain of rhodopsin occupies topologically extracellular (intradiscal) space and was not investigated in this study. BiFC generated by rhodopsin self-association was always robust, and although localized primarily and intensely to OSs, significant signals were commonly observed elsewhere as well. An initial self-association of rhodopsin at the biosynthetic level was suggested by a considerable presence of BiFC signals in ISs, including in cells with relatively modest overall expression. Distributions in the OS were consistent with protein incorporation into both OS disks and PM and frequently produced a banded 


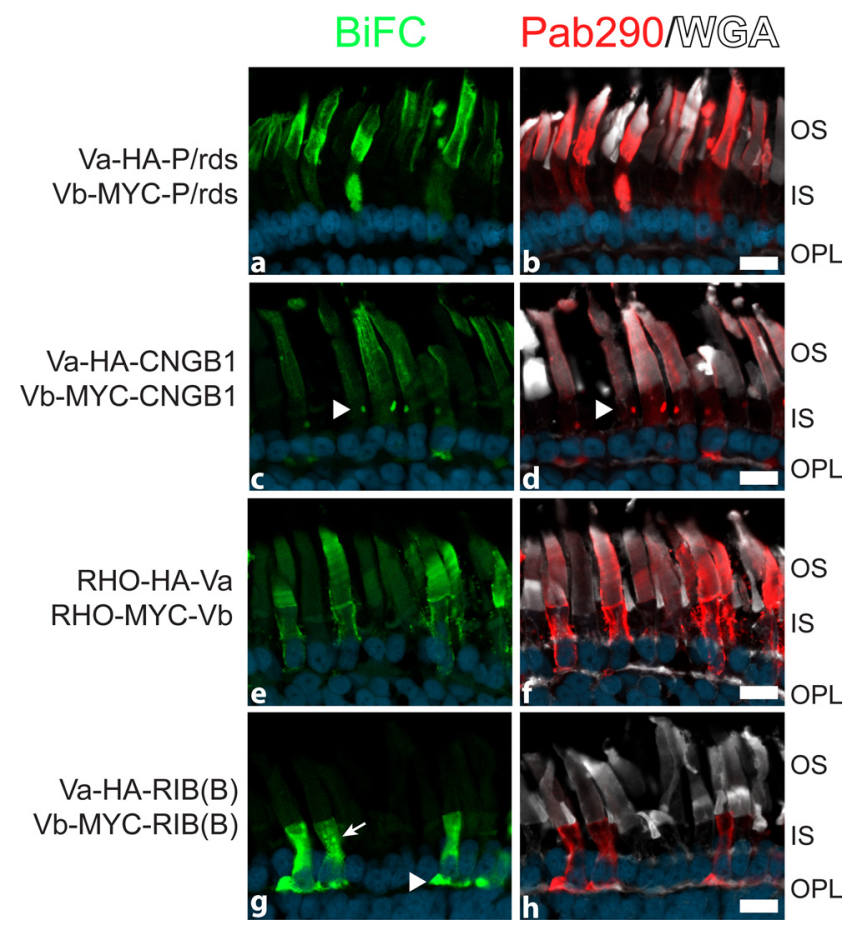

Figure 4. Self-assembly and trafficking of $O S$ and synaptic photoreceptor proteins fused to complementary Venus fragments produce distinctive patterns of BiFC. Confocal micrographs of tadpole ocular cryosections showing BiFC (green), WGA labeling of OSs (white), anti-GFP labeling of transgenic proteins (red), and Hoechst-stained nuclei (blue). Scale bars, $10 \mu \mathrm{m} . \mathrm{P} / \mathrm{rds}$ oligomerization (resulting from Va-HA-P/rds + Vb-MYC-P/rds coexpression) generated robust Venus-based BiFC, essentially similar to that observed when GFP fragments were used (Fig. 2C). The representative cells shown illustrate substantial diffuse complex formation in ISs, with more robust intensities present in OSs (a). CNGB1 homotetramerization (driven by Va-HACNGB1 + Vb-MYC-CNGB1 coexpression) also produced BiFC, although the signals generated were far less intense (c). Typical distributions included punctate accumulations within ISs (c, d, arrowheads) and more diffuse localization within OSs that highlighted incisures. Weak synaptic signals were also frequently observed in positive cells. Expression of complementary Venusrhodopsin partners (RHO-HA-Va + RHO-MYC-Vb) generated the most highly robust BiFC signals observed $(\boldsymbol{e})$. The most intense BIFC was OS localized; however, substantial signals were present in IS plasma membranes, IS vesicles, and synaptic regions. $\mathrm{RIB}(\mathrm{B})$ homotypic interactions (generated by $\mathrm{Va}-\mathrm{HA}-\mathrm{RIB}(\mathrm{B})+\mathrm{Vb}-\mathrm{MYC}-\mathrm{RIB}(\mathrm{B})$ coexpression) were observed to drive robust BiFC $(\boldsymbol{g})$, seen as diffuse and punctate Venus fluorescence within ISs ( $\boldsymbol{g}$, arrow) and intense accretions within synaptic terminals ( $\boldsymbol{g}$, arrowhead). The BiFC generated by selfassembly of each protein $[\mathrm{P} / \mathrm{rds}, \mathrm{CNGB1}, \mathrm{RHO}$, and $\mathrm{RIB}(\mathrm{B})]$ was distributed as a subset of the total transgenic protein present, as visualized by IHC labeling using Pab290 $(\boldsymbol{b}, \boldsymbol{d}, \boldsymbol{f}, \boldsymbol{h})$ in a given cell/retina.

pattern similar to transgenic expression of rhodopsin-GFP in photoreceptors documented previously (Moritz et al., 2001). More highly expressing cells also showed significant presence in IS PM, synaptic termini, and what appeared to be vesicles shed into the extracellular space. The broad distributions may reflect a masking of the rhodopsin C-terminal OS localization signal (Deretic et al., 1998) by the C-terminal fusion tags.

Finally, we analyzed transgenic coexpression of fusion proteins incorporating the RIBEYE (B) domain and complementary fragments of Venus. RIBEYE is distinguished from $\mathrm{P} / \mathrm{rds}$, CNGB1, and rhodopsin in being a soluble (vs membrane) protein, with a presynaptic (vs OS) localization. Since RIBEYE possesses multiple domains that can interact in a complex way with several partners (Magupalli et al., 2008), we used its (selfassociating) B domain as a simplified model. Substantial BiFC was produced in rod photoreceptors when complementary $\mathrm{RIB}(\mathrm{B})$ fusion proteins [Va-HA-RIB(B) + Vb-MYC-RIB(B)], were coexpressed (Fig. 4g). RIB(B) homotypic interaction gener- ated BiFC signals localized exclusively to IS and synaptic terminal regions, producing distributions unlike those generated by selfassembly of any of the other proteins examined. Although little or no signal was detected in OSs, BiFC was obvious both as diffuse fluorescence and as focal puncta (Fig. $4 g$, arrow) within ISs. Substantial accumulations were also present in the outer plexiform layer (OPL), likely representing localization within synaptic termini (Fig. 4g, arrowhead). These distributions are consistent with published studies of RIBEYE localization (Schmitz et al., 2000; Magupalli et al., 2008; Regus-Leidig et al., 2009); they further imply that RIB(B) oligomerization can occur within ISs before final assembly of ribbons at the synaptic terminus.

Overall, homotypic assembly of OS and synaptic photoreceptor proteins generated distinctive BiFC distributions consistent with their known assembly and localization properties. Although we commonly found heterogeneous BiFC distributions, the majority were associated with protein overexpression and photoreceptor cell structural defects (OS narrowing or fragmentation). Analyses in this study were restricted to cells with moderate expression levels and least-perturbed morphologies. Using antiepitope tag IHC (data not shown), we found that one fusion protein partner was typically expressed in a greater number of cells, and the second partner was present within a smaller and overlapping set. BiFC signals coincided with those cells in which both partners were expressed. Within a given BiFC-positive cell, one fusion protein appeared to be present in greater abundance, and $\mathrm{BiFC}$ signal was observed in areas where distribution of the second (less abundant) fusion protein overlapped that of the first. In sum, these findings suggest that BiFC can report on homotypic interactions and trafficking for a variety of integral membrane and cytoplasmic proteins residing in multiple compartments within transgenic vertebrate photoreceptors.

\section{In situ BiFC assay of heterotypic interactions underlying OS scaffolding}

GARP interactions with $\mathrm{P} / \mathrm{rd}$ s have been proposed to function for OS structural maintenance (Poetsch et al., 2001) and were recently shown to be essential for the establishment of normal OS architecture (Zhang et al., 2009). We reasoned that knowledge of where such interactions are initiated could aid understanding of how the protein complexes function for OS structure. Furthermore, we predicted that the high stability of mature BiFC complexes (Magliery et al., 2005) could provide a robust trap for substoichiometric, transient, and/or weak associations-properties expected for GARP-P/rds interaction.

Since GARPs are splice variants derived from a single gene, we initially tested the longest gene product, CNGB1. As shown in Figure $5 A a$, we found that coexpression of complementary CNGB1 and P/rds fusion proteins (Va-HA-CNGB1 + Vb-MYC$\mathrm{P} / \mathrm{rds}$ ) generated significant BiFC signals, typically localized to both ISs and OSs. The routine appearance of puncta within the ISs (Fig. 5Aa, arrowheads) suggested that initial interaction of CNGB1 with $\mathrm{P} / \mathrm{rds}$ occurred before transport to the OS. Because CNGB1 resides only in OS PM (Cook et al., 1989) and P/rds is restricted to OS disk rims (Molday et al., 1987), the incorporation of these BiFC complexes into rod OSs suggests that the CNGB1$\mathrm{P} / \mathrm{rds}$ association can bridge the cytoplasmic space between the two discontinuous membrane systems. A negative control experiment found that far less BiFC signal was generated by coexpression of complementary Venus fusion proteins, which included CNGB1 and rhodopsin (Va-HA-CNGB1 + RHO-MYC-Vb). Since these proteins are not thought to interact with each other specifically, the modest signal produced (Fig. 5Ad) likely repre- 
sents a form of assay promiscuity-a result of random collision and trapping rather than specific protein interaction.

Coexpression of the most prevalent GARP variant, GARP2, with $\mathrm{P} / \mathrm{rds}$ (VaHA-GARP2 + Vb-MYC-P/rds) also generated $\mathrm{BiFC}$ in rod photoreceptors. Interestingly however, $\mathrm{BiFC}$ distributions were unlike those generated by CNGB1 + $\mathrm{P} / \mathrm{rds}$ coexpression. Instead, Venus fluorescence produced by GARP2 and P/rds assembly was robust in OSs but rarely observed elsewhere (Fig. 5Ag). Identical distributions were produced regardless of whether Venus fragments were fused to the GARP2 $\mathrm{N}$ terminus or $\mathrm{C}$ terminus. These findings suggest the possibility that GARP2 assembles with P/rds at the base of the OS and demonstrate that $\mathrm{P} / \mathrm{rds}$ can discriminate between individual GARP variants (Fig. 5A, $a$ vs $g$ ). A negative control experiment shows that $\mathrm{P} / \mathrm{rds}$ did not assemble to a significant extent with $\mathrm{RIB}(\mathrm{B})$; coexpression of Va-HA-RIB(B) + Vb-MYC-P/ rds fusion proteins produced only very weak BiFC signals (Fig. $5 A j$ ).

The GARP2-P/rds interaction was examined further by using immunoreagents that highlighted IS and OS compartments (Fig. $5 B a-c$ ). An antibody directed against calnexin, a resident of the endoplasmic reticulum, was used to label ISs (red). Mab $1 G 9$, a novel reagent generated for this study and directed against endogenous frog $\mathrm{P} / \mathrm{rds}$, was used to label OSs (white). The BiFC signals (green) generated by association of transgenically expressed GARP2 and $\mathrm{P} /$ rds were clearly excluded from IS regions that contained calnexin and instead were only distributed within the $\mathrm{P} / \mathrm{rds}$ containing OSs. Finally, we examined the possibility that epitope masking caused the relatively weak MYC signals (Fig. 5A, $b$ and h) seen. Mab C6, an antibody that reacts with the $\mathrm{C}$ terminus of transgenic but not endogenous $\mathrm{P} / \mathrm{rds}$, was substituted for antiMYC antibody to label the MYC-tagged protein. Indeed, Mab C6 labeling of transgenic $\mathrm{P} / \mathrm{rds}$ (white) (Fig. 5Be) was far more robust than that observed using the MYC epitope tag (white) (Fig. 5Ah). These results suggest that $\mathrm{BiFC}$ complex formation could partially reduce MYC labeling by epitope masking, but otherwise reiterate previous results. In sum, our findings demonstrate that a BiFC assay can be applied in vertebrate photoreceptors to localize heterotypic protein interactions in situ. They further reveal that GARP variants can initiate interactions with $\mathrm{P} / \mathrm{rds}$ in differing cellular compartments and suggest the possibility that GARP2-P/rds interaction first occurs at the level of nascent disk morphogenesis.

\section{Domain-level analysis of protein-protein interaction}

Given that both homomeric and heteromeric protein-protein interactions could be visualized in situ using BiFC, we applied the
A
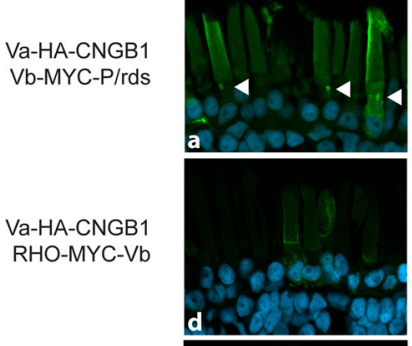

Va-HA-GARP2 Vb-MYC-P/rds

Va-HA-RIB(B) $\mathrm{Vb}-\mathrm{MYC}-\mathrm{P} / \mathrm{rds}$
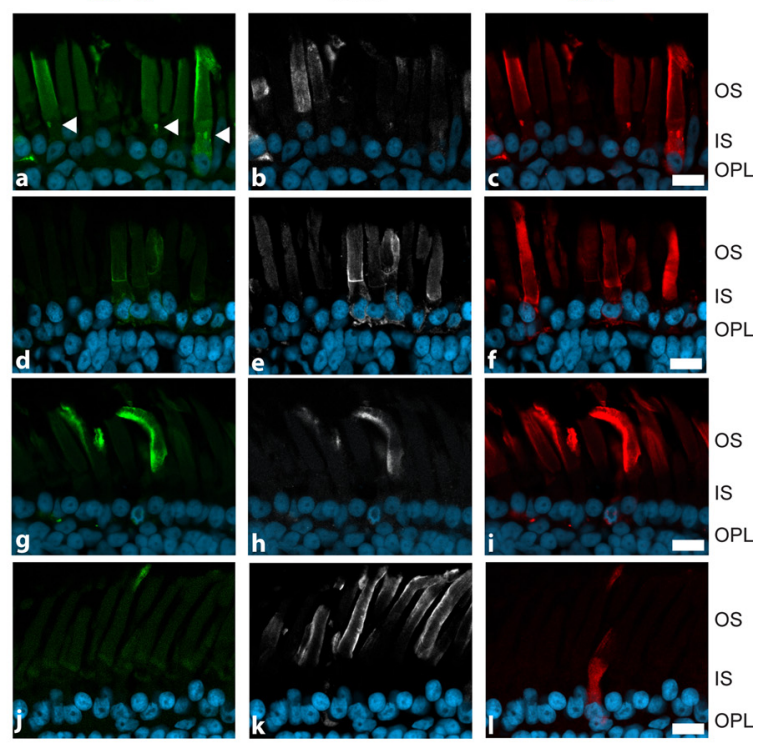

B

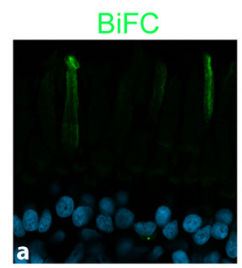

Ma(b)1G9/Calnexin
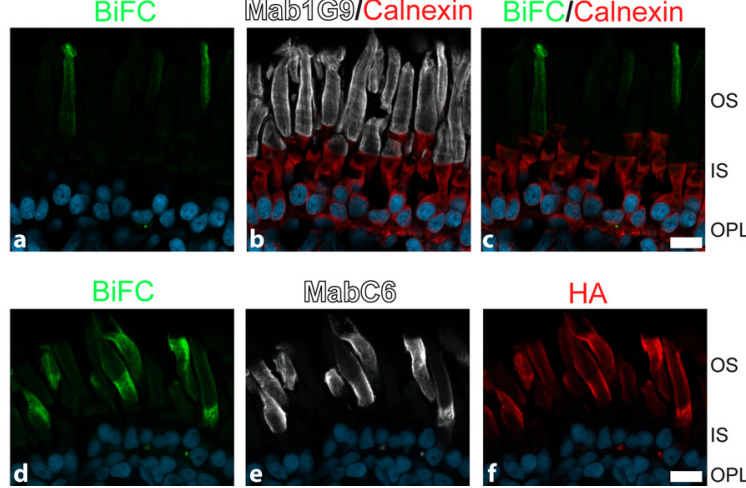

Ma!b(6)
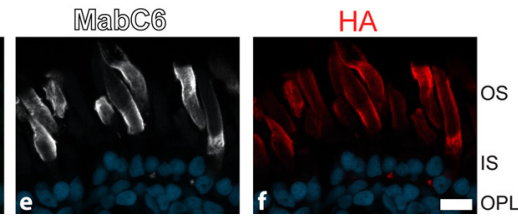

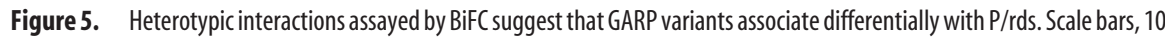
$\mu \mathrm{m} . \boldsymbol{A}$, Confocal micrographs of tadpole ocular cryosections showing BiFC (green; $\boldsymbol{a}, \boldsymbol{d}, \boldsymbol{g}, \boldsymbol{j}$ ), antibody labeling of MYC-tagged (white; $\boldsymbol{b}, \boldsymbol{e}, \boldsymbol{h}, \boldsymbol{k}$ ) and HA-tagged (red; $\boldsymbol{C}, \boldsymbol{f}, \boldsymbol{i}, \boldsymbol{I})$ fusion proteins and Hoechst-stained nuclei (blue; $\boldsymbol{a}-\boldsymbol{I}$ ). Coexpression of P/rds with CNGB1 or GARP2, but not rhodopsin or RIB(B), generated significant BiFC; subcellular distributions were dependent on which GARP was used. Assembly of Vb-MYC-P/rds with complementary fusion protein Va-HA-CNGB1, but not Va-HA-GARP2, drove BiFC

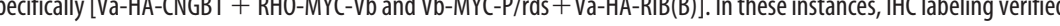
(Mab 1G9, white) and ER-resident protein calnexin (SPA-865, red), and Hoechst-stained nuclei (blue) (blue). Expression of the transgenic proteins resulted in BiFC complexes visualized in OSs $(\boldsymbol{a}, \boldsymbol{d})$; no effects on distribution of epitope $\operatorname{tag}(\boldsymbol{A}, \boldsymbol{b}$ and $\boldsymbol{h})$. An antibody directed against the unique $($ terminus of transgenic $\mathrm{bP} / \mathrm{rds}(\boldsymbol{e})$ validates the presence of masking, demonstrates a robust expression of V2-MYC-P/rds, and confirms normal trafficking and localization.

approach to investigate an individual protein structure/function relationship. We focused on $\mathrm{P} / \mathrm{rds}$, since it functions in an OSspecific manner and is therefore particularly challenging to assay when expressed ectopically (i.e., in cells other than photoreceptors). Several important functions have been ascribed to its intrinsically disordered 66 aa C terminus (Boesze-Battaglia et al., 1998; Ritter et al., 2004, 2005), and given previous evidence, we predicted that deletion of this domain would remove a localization signal (Tam et al., 2004) but leave global protein structure intact (Ritter et al., 2005; Lee et al., 2006). Figure 6 shows application of the Venus-based BiFC assay to a P/rds C-terminal deletion mutant in transgenic $X$. laevis photoreceptors. 
A

Va-HA-P/rds Vb-MYC-P/rds

Va-HA-P/rds $\triangle \mathrm{C}$ Vb-MYC-P/rds $\Delta \mathrm{C}$

B

Va-HA-P/rds $\Delta C$ Vb-MYC-P/rds

Va-HA-P/rds $\Delta \mathrm{C}$ Vb-MYC-P/rds $\triangle \mathrm{C}$

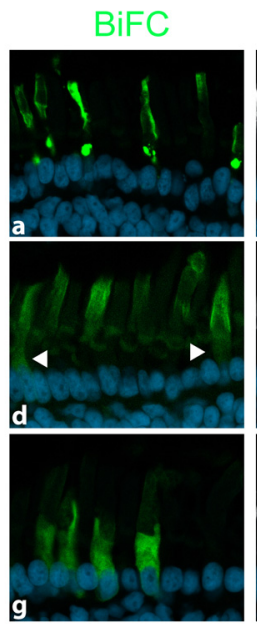

BiFC
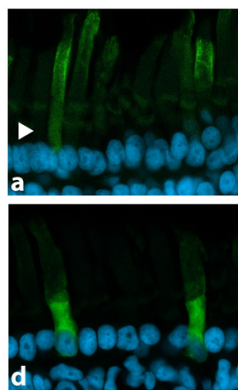

Mab1G9

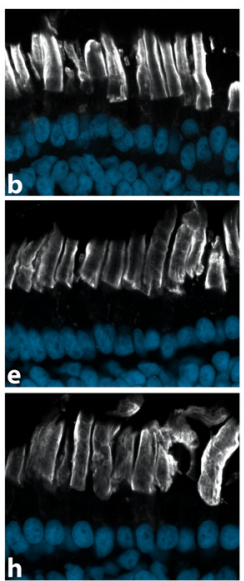

HA
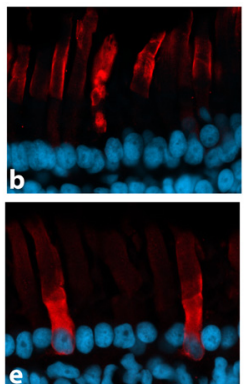

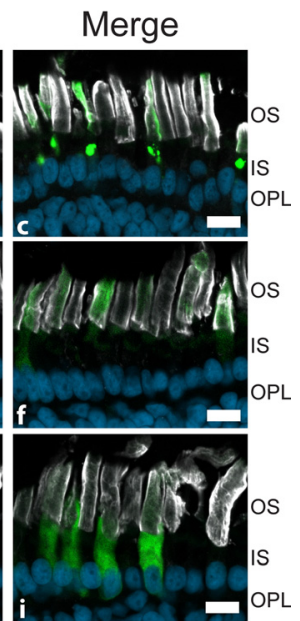

MYC

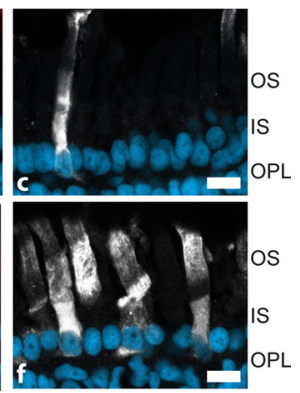

Figure 6. Role of the $P / r d s C$ terminus for self-assembly and localization. Scale bars, $10 \mu \mathrm{m}$. $\boldsymbol{A}$, Confocal micrographs of tadpole ocular cryosections showing BiFC (green; $\boldsymbol{a}, \boldsymbol{d}, \boldsymbol{g})$, Mab $1 \mathrm{G} 9$ labeling of endogenous X. laevis P/rds (white; $\boldsymbol{b}, \boldsymbol{e}, \boldsymbol{h}$ ), and Hoechst stained nuclei (blue; $\boldsymbol{a}-\boldsymbol{i})$. Deletion of the $\mathrm{P} / \mathrm{rds}$ C-terminal domain from one (Va-HA-P/rds $\Delta \mathrm{C}+\mathrm{Vb}-\mathrm{MYC}-\mathrm{P} / \mathrm{rds}$ ) or both (Va-HA-P/rds $\Delta \mathrm{C}+\mathrm{Vb}-\mathrm{MYC}-\mathrm{P} / \mathrm{rds} \Delta \mathrm{C}$ ) transgenically expressed proteins did not prevent self-assembly; substantial BiFC was generated in each instance $(\boldsymbol{a}, \boldsymbol{d}, \boldsymbol{g})$. In contrast, absence of the C-terminal domain tended to favor IS localization ( $\boldsymbol{d}$, arrowheads) in a dose-dependent manner. $\boldsymbol{B}$, Confocal micrographs of tadpole ocular cryosections showing, in $\boldsymbol{a}-\boldsymbol{C}$, BiFC (green), antibody labeling of HA-tagged (red) and MYC-tagged (white) fusion proteins, and Hoechst stained nuclei (blue), or $\boldsymbol{d}-\boldsymbol{f}$, BiFC (green), HA labeling of Va-HA-P/rds $\Delta C$ (red), MabC6 labeling of Vb-MYC-P/rds (white), and Hoechst stained nuclei (blue). Labeling of individual transgenic proteins ( $\boldsymbol{e}$ and $\boldsymbol{f} \boldsymbol{v} \boldsymbol{b}$ and $\boldsymbol{c}$ ) showed that loss of (-terminal domains produced a somewhat greater effect on BiFC complex than individual partner distributions.

Figure 6 shows ocular cryosections from transgenic tadpoles coexpressing complementary Venus fragments fused to wildtype (WT) P/rds (Va-HA-P/rds + Vb-MYC-P/rds), mutant $\mathrm{P} / \mathrm{rds}$ lacking its $\mathrm{C}$ terminus in combination with WT (Va-HA$\mathrm{P} / \mathrm{rds} \Delta \mathrm{C}+\mathrm{Vb}-\mathrm{MYC}-\mathrm{P} / \mathrm{rds}$ ), or the mutant version alone (Va$\mathrm{HA}-\mathrm{P} / \mathrm{rds} \Delta \mathrm{C}+\mathrm{Vb}-\mathrm{MYC}-\mathrm{P} / \mathrm{rds} \Delta \mathrm{C}$ ). OSs were highlighted by labeling the endogenous frog $\mathrm{P} /$ rds with Mab 1G9. Coexpression of complementary proteins generated significant $\mathrm{BiFC}$ in each instance (Fig. 6Aa,d,g). These findings are consistent with previous reports that extracellular determinants mediate $\mathrm{P} / \mathrm{rds}$ subunit assembly and the cytoplasmic C terminus does not (Goldberg et al., 2001; Ding et al., 2005). Interestingly, loss of the $\mathrm{C}$ terminus from a single partner had relatively little effect on BiFC (Fig. 6A, $d v s a$ ); signals within ISs appeared somewhat more diffuse than those produced by full-length $\mathrm{P} / \mathrm{rds}$ partners. In contrast, loss of $\mathrm{C}$ termini from both partners dramatically altered BiFC distributions. In this case, complexes were localized in a diffuse pattern almost entirely within ISs (Fig. 6A, $g$ vs $a$ ). Little or no BiFC fluorescence was found associated with OSs. Loss of OS localization is consistent with a previously demonstrated role for the $\mathrm{P} / \mathrm{rds} \mathrm{C}$ terminus in trafficking (Tam et al., 2004).

To investigate this effect in more detail, we conducted epitope tag analyses of the individual fusion proteins for cotransgenic

animals expressing the C-terminal deletion mutant with no or one copy of fulllength $\mathrm{P} / \mathrm{rds}$ (Fig. 6B). IHC localization showed that each partner overlapped but was not identical with the distribution of BiFC complexes. Examination of distributions for $\mathrm{P} / \mathrm{rds}$ mutants completely lacking $\mathrm{C}$ termini suggest that the noncomplexed fractions of each partner had a somewhat greater tendency to be OS localized, relative to the fractions assembled into complexes. Because P/rds self-assembly occurs at several stages, this observation may reflect the ability of BiFC complex formation to inhibit interaction of transgenic $\mathrm{P} /$ rds with endogenous $\mathrm{P} / \mathrm{rds}$.

We were curious to know whether and to what extent the transgenic proteins investigated here were interacting with their endogenous counterparts. A previous study (Loewen et al., 2003) suggests that interactions between bovine and Xenopus $\mathrm{P} / \mathrm{rds}$ orthologs can occur in transgenic $X$. laevis but based its conclusions on proteins expressed in cultured cells. Our current finding, that BiFC complexes formed by $\mathrm{P} / \mathrm{rds} \Delta \mathrm{C}$ self-association are not trafficked to the OS (Fig. 6Ag, Bd), implies that the transgenically expressed proteins remain largely unassociated with endogenous $\mathrm{P} / \mathrm{rds}$. Since no direct measurements of potential interactions between transgenic and endogenous $\mathrm{P} / \mathrm{rds}$ in $X$. laevis have been reported to date, we developed a novel immunoaffinity matrix to address this question.

Figure $7 A$ shows the results of an immunoprecipitation experiment using a Triton X-100 extract from WT tadpole eyes in conjunction with Mab 1G9 covalently linked to Sepharose beads. This matrix efficiently depletes the eye extract of endogenous $\mathrm{xP} / \mathrm{rds}$, which was recovered in the SDS-eluted fraction (ELU2). If a small amount of Triton X-100solubilized bovine ROS membranes (containing native $\mathrm{bP} / \mathrm{rds}$ ) was added to the eye extract before immunoprecipitation, the $\mathrm{bP} / \mathrm{rds}$ remained in the unbound fraction. These results demonstrate the specificity of the Mab 1G9 matrix under our immunoprecipitation conditions and further demonstrate that detergent-solubilized $\mathrm{P} / \mathrm{rds}$ from $X$. laevis and bovine ROS membranes show no tendency to associate.

We then used the Mab 1G9 matrix to immunopurify endogenous $\mathrm{P} / \mathrm{rds}$ from transgenic tadpole eyes coexpressing complementary Venus fragments fused to the following: (1) bP/rds lacking its $\mathrm{C}$ terminus (Va-HA-bP/rds $\Delta \mathrm{C}$ ); and (2) full-length $\mathrm{bP} / \mathrm{rds}$ (Vb-MYC-bP/rds). Western blot analysis was used to assay whether either of the transgenically expressed proteins copurified with the $X$. laevis $\mathrm{P} / \mathrm{rds}$. To our surprise, the vast majority (i.e., $>90 \%$ ) of both fusion proteins (detected with anti-GFP antisera) remained in the unbound fraction (Fig. $7 B$ ) despite the nearly quantitative removal of endogenous $\mathrm{P} / \mathrm{rds}$. The clear lack of association was not a result of the $\mathrm{P} / \mathrm{rds}$ truncation mutation or fusion of Venus fragments to protein $\mathrm{N}$ termini, since experiments performed with coexpressed full-length $\mathrm{P} / \mathrm{rds}$ fusions pro- 
A IP: xP/rds (Mab1G9)

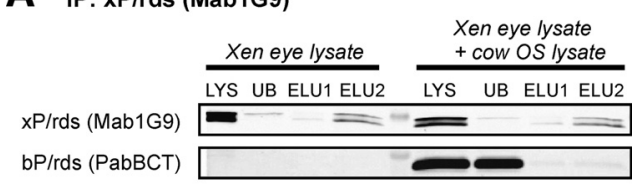

B IP: xP/rds (Mab1G9)

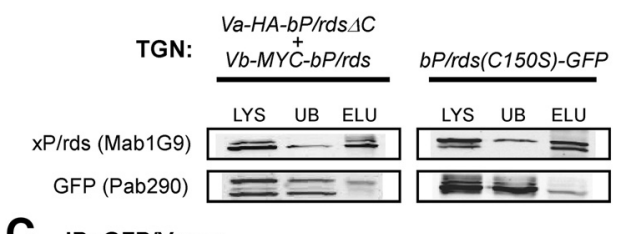

C IP: GFP/Venus

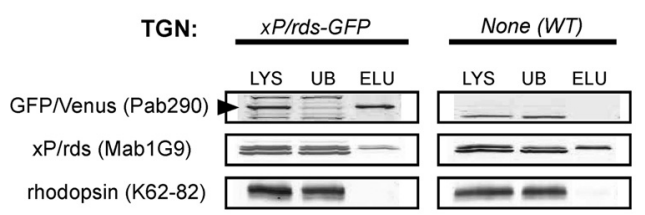

D IP: GFP/Venus

\begin{aligned} & TGN: $\begin{array}{l}\text { Va-HA-bP/rds } \triangle C \\ \text { Vb-MYC-bP/rds }\end{array} \\ &$\cline { 2 - 2 } LYS UB ELU \\ & HA (Pab9110) \\ & bP/rds (MabC6) \\ & xP/rds (Mab1G9) \end{aligned}

Figure 7. Immunoprecipitation analyses demonstrate a segregated assembly of transgenic proteins. Reactions were assayed by Western blotting using the indicated antibodies; blots represent quantitative comparison of: detergent lysate (LYS), unbound supernatant (UB), and eluted (ELU) fractions. A, A novel monoclonal antibody, Mab 1G9, was developed to the $C$ terminus of $\mathrm{xP} / \mathrm{rds}$ (xrds38) and was used to immunoprecipitate (IP) the protein from Triton $X-100$ tadpole eye extracts under nonreducing conditions. The endogenous protein (most commonly observed as a doublet) could be effectively depleted from lysates (UB) and then recovered following SDS (ELU1), but not acid (ELU2) elution of beads. Importantly, Mab 1G9 showed no cross-reactivity with bP/rds. We found that bP/rds (detected with ortholog-specific MabC6) remained in lysates from which XP/rds was efficiently removed. $\boldsymbol{B}$, Left, Immunoprecipitation of endogenous XP/rds from transgenic tadpole eyes coexpressing complementary Venus fragments fused to the following: (1) bP/rds lacking its ( terminus (Va-HA-bP/rds $\Delta C$ ); and (2) full-length $\mathrm{bP} / \mathrm{rds}$ (Vb-MYC-bP/rds). The vast majority of each transgenic fusion protein (detected with polyclonal antibody Pab290) failed to coprecipitate. Right, Immunoprecipitation of endogenous $\mathrm{xP} / \mathrm{rds}$ from transgenic tadpole eyes expressing $\mathrm{bP} / \mathrm{rds}$ fused to full-length GFP protein at its C terminus (bP/rds-C150S-GFP). Little or no coprecipitation with endogenous XP/rds was observed. C, Reciprocal immunoprecipitation performed with an anti-GFP matrix confirms segregated assembly. Left, Immunoprecipitation of a XP/rds-GFP fusion protein from transgenic tadpole eyes. Transgenically expressed fusion protein (detected with polyclonal antibody Pab290) was efficiently immunoprecipitated; however, neither endogenous XP/rds (detected with Mab 1G9) or rhodopsin (K62-82) was coprecipitated. Right, What appeared to be a minor amount of coprecipitating $\mathrm{xP} / \mathrm{rds}$ was in fact, a cross-reacting protein also present in WT tadpole eye lysates. $\boldsymbol{D}$, Assembly of a P/rds C-terminal deletion mutant. A reciprocal immunoprecipitation performed using the lysate detailed in $\boldsymbol{B}$ above (coexpressed $\mathrm{Va}-\mathrm{HA}-\mathrm{bP} / \mathrm{rds} \Delta \boldsymbol{C}$ and Vb-MYC-bP/rds). BiFC complexes were collected using an anti-GFP/Venus matrix and blotted for individual fusion protein partners. Although transgenic proteins coprecipitate with each other, endogenous $\mathrm{P} / \mathrm{rds}$ does not. MabC6 binds the $\mathrm{C}$ terminus of $\mathrm{bP} / \mathrm{rds}$ and therefore is specific to the full-length protein.

teins and those to which C-terminal fusions of GFP had been made showed identical behavior (data not shown). We wondered whether use of a split fluorophore contributed to the lack of assembly and repeated the experiment using a lysate from transgenic tadpole eyes expressing a single fusion protein with fulllength GFP protein at its $\mathrm{C}$ terminus (bP/rds-C150S-GFP). This mutant version of $\mathrm{P} /$ rds does not form disulfide-linked oligomers but otherwise shows normal tetramerization (Goldberg et al., 1998; Loewen and Molday, 2000). Like other transgenic constructs, it too did not assemble with endogenous $\mathrm{P} /$ rds.

We then wondered whether the species difference between the transgenic and endogenous proteins was responsible for the lack of protein coassembly. Figure $7 C$ shows the result of an immunoprecipitation of transgenically expressed $X$. laevis $\mathrm{P} / \mathrm{rds}-\mathrm{GFP}$ from tadpole eyes. Here, we used an anti-GFP matrix that bound folded GFP (Rothbauer et al., 2008) to avoid potential antibody cross-reactivity issues. Despite nearly quantitative binding and elution of the $66 \mathrm{kDa}$ transgenic fusion protein (Fig. 7C, arrowhead), virtually all of the endogenous $\mathrm{xP} / \mathrm{rds}$ remained in the unbound fraction. What appears to be a minor amount of endogenous coprecipitating $\mathrm{xP} / \mathrm{rds}$ turned out to be a cross-reacting protein present in WT tadpole eye lysates as well (Fig. $7 C$, right). Finally, we tested for association between coexpressed transgenic proteins. BiFC complexes were collected using an anti-GFP matrix and reactions were analyzed by Western blotting to follow individual transgenic proteins. The results (Fig 7D) show a clear coprecipitation of Va-HA-bP/rds $\Delta \mathrm{C}$ with $\mathrm{Vb}-\mathrm{MYC}-\mathrm{bP} / \mathrm{rds}$; however, the complexes do not contain endogenous $\mathrm{xP} / \mathrm{rds}$. These results are consistent with our other findings, and provide independent lines of evidence that show the following: (1) transgenic bP/rds assembles with itself but not with endogenous $\mathrm{xP} / \mathrm{rds}$; and 2) the $\mathrm{P} / \mathrm{rds}$ $\mathrm{C}$ terminus is not essential for self-assembly. In sum, our observations indicate that a wide variety of $\mathrm{P} / \mathrm{rd}$ s fusion proteins have little or no tendency to assemble with their endogenous counterpart in transgenic $X$. laevis rod photoreceptors.

\section{Discussion}

Despite significant progress in identifying proteins that contribute to the normal architecture of photoreceptor OSs (Kennedy and Malicki, 2009; Sung and Chuang, 2010), an integrated view of the molecular mechanisms that structure and renew these specialized cilia remains to be established. We have developed a new approach suitable for investigating both membrane and soluble protein interactions in intact vertebrate photoreceptors. Initially used for analyses in bacteria (Ghosh et al., 2000), fluorescence complementation has since been adapted for use in plant, fungal, and cultured mammalian cell-expression systems ( $\mathrm{Hu}$ et al., 2002; Nyfeler et al., 2005; Kerppola, 2008). It has not, to our knowledge, been implemented in vertebrate sensory neurons to date.

We initially developed our BiFC assay in cultured cells using complementary GFP fragments fused to P/rds, GARP2, and rhodopsin, but found it necessary to redesign the expression constructs using fragments based on Venus, a more highly fluorescent protein. The Venus-based BiFC assay allowed detection of weak homotypic interactions not observable using GFP fragments. The visualization of GARP2 and P/rds heterotypic interaction by this means represents the first demonstration that additional photoreceptor-specific proteins are not required for this association. We used the rod opsin promoter (Knox et al., 1998 ) to coexpress BiFC constructs in transgenic X. laevis rod photoreceptors and provide a proof-of-principle demonstration that protein interactions can be visualized in situ. Robust BiFC signals driven by $\mathrm{P} / \mathrm{rds}$ self-assembly were initiated at the biosynthetic level and trafficked into OSs; these results are consistent with previous suggestions that the initial stages of $\mathrm{P} / \mathrm{rds}$ assembly take place at the biosynthetic level (Goldberg et al., 1995; Loewen et al., 2003; Chakraborty et al., 2008). P/rds incorporated into BiFC complexes, unlike uncomplexed protein, showed substantial presence within ISs. The mechanisms underlying this differ- 
ential processing are not evident; however, they may include slowed trafficking and/or retention of a misfolded fraction of the population. Dynamic imaging of BiFC complexes in live cells may help distinguish between these possibilities.

To determine whether the in situ assay could be applied more generally, we used Venus-based BiFC fragments in conjunction with CNGB1, rhodopsin, and RIBEYE, three additional (and essential) photoreceptor proteins known to self-associate. Each generated a distinctive subcellular distribution pattern of BiFC in situ consistent with its known properties. CNGB1 generated BiFC within the IS layer consistent with channel subunit assembly within the endoplasmic reticulum (Deutsch, 2002), and complexes were trafficked to OS PM, the normal site of localization of protein function (Cook et al., 1989). Future studies could take advantage of this approach to assay pathogenic mutations proposed to affect channel subunit assembly and targeting. Rhodopsin self-association produced intense BiFC signals that were the most widely distributed of any observed and similar to those resulting from deletion of the rhodopsin localization signal (Moritz et al., 2001). Since uncomplexed rhodopsin fusion protein showed a similarly broad distribution (Fig. 5Ae), it seems likely that the fusion constructs used here masked the C-terminal localization signal (Deretic et al., 1998). Therefore, the current results may over-represent the degree to which this protein selfassociates. The modest levels of BiFC produced by rhodopsin self-association in cultured cells are consistent with this idea. Redesigning the fusion protein by reducing its expression in $X$. laevis (e.g., substituting a weaker promoter) could address this issue in future studies. RIB(B) self-association generated BiFC complexes evident within ISs but more intensely concentrated within synaptic termini-distributions consistent with RIBEYE function as the major constituent of synaptic ribbons (Schmitz et al., 2000). These data suggest that RIBEYE monomers oligomerize at the level of the IS before being transported to the OPL. This model is similar to one proposed previously (Regus-Leidig et al., 2009); that study proposed an assembly of RIBEYE precursor spheres within the IS- before trafficking and assembly into synaptic ribbons. Since the RIB(B) domain examined here is largely similar to CtBP2, a splice variant of the gene from which RIBEYE is derived (Schmitz et al., 2000), additional studies are required to dissect individual contributions made by the two gene products.

We applied the in situ BiFC approach to investigate a reported interaction of GARPs with $\mathrm{P} / \mathrm{rds}$, a candidate for organizing rod cell OS structure (Poetsch et al., 2001). The Venus-based assay responded robustly and specifically; associations between $\mathrm{P} / \mathrm{rds}$ and GARPs (Fig. 5Aa), but not P/rds and RIBEYE (Fig. $5 A j$ ) or GARPs and rhodopsin (Fig. $5 A d$ ), were clearly visualized. The results provide an independent validation of GARP-P/rds interaction, originally identified via immunoprecipitation (Poetsch et al., 2001). They also provide the first demonstration that this interaction occurs in vivo and that individual GARP variants behave dissimilarly with regard to P/rds. CNGB1 assembled with $\mathrm{P} / \mathrm{rds}$ in the IS, while GARP2 interaction with $\mathrm{P} / \mathrm{rds}$ appeared to initiate in the OS. This differential interaction suggests distinct modes of binding. Interestingly, P/rds (Ritter et al., 2005) and GARPs (Batra-Safferling et al., 2006) are each characterized by intrinsic disorder - a structural plasticity that allows for binding to multiple targets (Dyson and Wright, 2002; Dunker et al., 2005). It is plausible that intrinsic disorder underlies differential binding of GARP variants to $\mathrm{P} / \mathrm{rds}$; it is also possible that $\mathrm{P} / \mathrm{rds}$ interacts with a CNGB1 region other than its glutamic acid-rich domain.

It is plausible that differential interactions of GARPs with $\mathrm{P} / \mathrm{rds}$ support normal OS structure and contribute to inherited disease phenotypes. We speculate that GARP2 assembly with $\mathrm{P} / \mathrm{rds}$ at the basal OS can stabilize disk-disk fibrils (Roof and Heuser, 1982) established during disk morphogenesis. This hypothesis is consistent with a recent finding that normal OS architecture cannot be established in the complete absence of GARPs (Zhang et al., 2009). Assembly at the level of the OS is also consistent with the notion that GARP2 functions to scaffold and modulate phototransduction proteins, such as PDE6 (Körschen et al., 1999; Pentia et al., 2006). In contrast, our observation that CNGB1 assembles with $\mathrm{P} / \mathrm{rds}$ at a stage before disk morphogenesis leads us to conjecture that this association primarily functions to localize CNGB1 in the vicinity of disk rims. The stabilization of OS structure that this interaction provides for older photoreceptors (Hüttl et al., 2005) is likely a secondary or indirect consequence. CNG channel immobilization in OS plasma membrane is documented (Biel et al., 1996; Körschen et al., 1999). Finally, this model suggests that mutations affecting interaction of GARPs with $\mathrm{P} / \mathrm{rds}$ could produce variable disease outcomes, with defects affecting GARP2 interaction potentially being more severe than those affecting CNGB1 interaction. Broad phenotypic heterogeneity is a hallmark of inherited defects in $\mathrm{P} /$ rds (Boon et al., 2008).

We were surprised to find that transgenic $\mathrm{P} / \mathrm{rds}$ did not assemble to a significant extent with its endogenous counterpart in $X$. laevis photoreceptors. Reciprocal immunoprecipitation experiments showed that none of the transgenically expressed (bovine or $X$. laevis) $\mathrm{P} / \mathrm{rds}$ proteins interacted to an appreciable extent with endogenous $\mathrm{xP} /$ rds. Furthermore, in situ $\mathrm{BiFC}$ experiments demonstrated that a transgenically expressed $\mathrm{P} / \mathrm{rds}$ mutant lacking its $\mathrm{C}$ terminus $(\mathrm{P} / \mathrm{rds} \Delta \mathrm{C})$ was trafficked independently of endogenous $\mathrm{P} / \mathrm{rds}$. Together, these data compel us to conclude that $X$. laevis photoreceptors can distinguish between transgenic and endogenous $\mathrm{P} / \mathrm{rds}$. Interestingly, transgenic mouse photoreceptors show a similar behavior; $\mathrm{bP} / \mathrm{rds}$ expressed on a WT mouse background is fully functional, yet does not coassemble with the endogenous protein (Goldberg et al., 2007). Therefore, it appears that transgenic $\mathrm{P} / \mathrm{rds}$ can function in a "separate but equal" manner. We conjecture that a spatiotemporal segregation of transgenic $\mathrm{P} / \mathrm{rds}$ may limit its coassembly with the endogenous protein; additional studies are needed to test this idea.

We have developed and applied a novel approach for investigating protein-protein interactions in situ; it offers a unique window into the dynamic architecture of the photoreceptor OS. Our findings suggest that GARP variants may play multiple roles for OS scaffolding: first by tethering plasma membrane ion channels and exchangers near to localized signaling processes at disk rims, and second by contributing to the stability of multiprotein complexes that mediate disk morphogenesis and stacking. Application of the method to other essential and disease-related proteins (including rhodopsin, RIBEYE, and a $\mathrm{P} / \mathrm{rds}$ deletion mutant) shows that protein oligomerization at the biosynthetic level is a common theme in photoreceptors and illustrates the broad potential this method offers for the analysis of wild-type and mutant protein assembly, structure/function relationships, and trafficking within the normal cellular milieu of sensory neurons.

\section{References}

Batra-Safferling R, Abarca-Heidemann K, Körschen HG, Tziatzios C, Stoldt M, Budyak I, Willbold D, Schwalbe H, Klein-Seetharaman J, Kaupp UB (2006) Glutamic acid-rich proteins of rod photoreceptors are natively unfolded. J Biol Chem 281:1449-1460.

Berger W, Kloeckener-Gruissem B, Neidhardt J (2010) The molecular basis of human retinal and vitreoretinal diseases. Prog Retin Eye Res 29:335-375. 
Biel M, Zong X, Ludwig A, Sautter A, Hofmann F (1996) Molecular cloning and expression of the modulatory subunit of the cyclic nucleotide-gated cation channel. J Biol Chem 271:6349-6355.

Boesze-Battaglia K, Lamba OP, Napoli AA Jr, Sinha S, Guo Y (1998) Fusion between retinal rod outer segment membranes and model membranes: a role for photoreceptor peripherin/rds. Biochemistry 37:9477-9487.

Bok D, Young RW (1972) The renewal of diffusely distributed protein in the outer segments of rods and cones. Vision Res 12:161-168.

Boon CJ, den Hollander AI, Hoyng CB, Cremers FP, Klevering BJ, Keunen JE (2008) The spectrum of retinal dystrophies caused by mutations in the peripherin/RDS gene. Prog Retin Eye Res 27:213-235.

Burns ME, Arshavsky VY (2005) Beyond counting photons: trials and trends in vertebrate visual transduction. Neuron 48:387-401.

Chakraborty D, Ding XQ, Fliesler SJ, Naash MI (2008) Outer segment oligomerization of Rds: Evidence from mouse models and subcellular fractionation. Biochemistry 47:1144-1156.

Clarke G, Goldberg AF, Vidgen D, Collins L, Ploder L, Schwarz L, Molday LL, Rossant J, Szél A, Molday RS, Birch DG, McInnes RR (2000) Rom-1 is required for rod photoreceptor viability and the regulation of disk morphogenesis. Nat Genet 25:67-73.

Colville CA, Molday RS (1996) Primary structure and expression of the human beta-subunit and related proteins of the rod photoreceptor cGMPgated channel. J Biol Chem 271:32968-32974.

Connell G, Bascom R, Molday L, Reid D, McInnes RR, Molday RS (1991) Photoreceptor peripherin is the normal product of the gene responsible for retinal degeneration in the rds mouse. Proc Natl Acad Sci U S A $88: 723-726$.

Cook NJ, Molday LL, Reid D, Kaupp UB, Molday RS (1989) The cGMPgated channel of bovine rod photoreceptors is localized exclusively in the plasma membrane. J Biol Chem 264:6996-6999.

Corless JM, Fetter RD (1987) Structural features of the terminal loop region of frog retinal rod outer segment disk membranes: III. Implications of the terminal loop complex for disk morphogenesis, membrane fusion, and cell surface interactions. J Comp Neurol 257:24-38.

Deretic D, Schmerl S, Hargrave PA, Arendt A, McDowell JH (1998) Regulation of sorting and postGolgi trafficking of rhodopsin by its C-terminal sequence QVS(A)PA. Proc Natl Acad Sci U S A 95:10620-10625.

Deutsch C (2002) Potassium channel ontogeny. Annu Rev Physiol 64:19-46.

Ding XQ, Stricker HM, Naash MI (2005) Role of the second intradiscal loop of peripherin/rds in homo and hetero associations. Biochemistry 44:4897-4904.

Dunker AK, Cortese MS, Romero P, Iakoucheva LM, Uversky VN (2005) Flexible nets. The roles of intrinsic disorder in protein interaction networks. FEBS J 272:5129-5148.

Dyson HJ, Wright PE (2002) Coupling of folding and binding for unstructured proteins. Curr Opin Struct Biol 12:54-60.

Fliegauf M, Benzing T, Omran H (2007) When cilia go bad: cilia defects and ciliopathies. Nat Rev Mol Cell Biol 8:880-893.

Fotiadis D, Liang Y, Filipek S, Saperstein DA, Engel A, Palczewski K (2004) The $\mathrm{G}$ protein-coupled receptor rhodopsin in the native membrane. FEBS Lett 564:281-288.

Ghosh I, Hamilton AD, Regan L (2000) Antiparallel leucine zipper-directed protein reassembly: application to the green fluorescent protein. J Am Chem Soc 122:5658-5659.

Goldberg AF (2006) Role of peripherin/rds in vertebrate photoreceptor architecture and inherited retinal degenerations. Int Rev Cytol 253:131-175.

Goldberg AF, Moritz OL, Molday RS (1995) Heterologous expression of photoreceptor peripherin/rds and Rom- 1 in COS- 1 cells: assembly, interactions, and localization of multisubunit complexes. Biochemistry 34:14213-14219.

Goldberg AF, Loewen CJ, Molday RS (1998) Cysteine residues of photoreceptor peripherin/rds: role in subunit assembly and autosomal dominant retinitis pigmentosa. Biochemistry 37:680-685.

Goldberg AF, Fales LM, Hurley JB, Khattree N (2001) Folding and subunit assembly of photoreceptor peripherin/rds is mediated by determinants within the extracellular/intradiskal EC2 domain: implications for heterogeneous molecular pathologies. J Biol Chem 276:42700-42706.

Goldberg AF, Ritter LM, Khattree N, Peachey NS, Fariss RN, Dang L, Yu M, Bottrell AR (2007) An intramembrane glutamic acid governs periph- erin/rds function for photoreceptor disk morphogenesis. Invest Ophthalmol Vis Sci 48:2975-2986.

Hu CD, Chinenov Y, Kerppola TK (2002) Visualization of interactions among bZIP and Rel family proteins in living cells using bimolecular fluorescence complementation. Mol Cell 9:789-798.

Hüttl S, Michalakis S, Seeliger M, Luo DG, Acar N, Geiger H, Hudl K, Mader R, Haverkamp S, Moser M, Pfeifer A, Gerstner A, Yau KW, Biel M (2005) Impaired channel targeting and retinal degeneration in mice lacking the cyclic nucleotide-gated channel subunit CNGB1. J Neurosci 25:130-138.

Kajimura N, Harada Y, Usukura J (2000) High-resolution freeze-etching replica images of the disk and the plasma membrane surfaces in purified bovine rod outer segments. J Electron Microsc (Tokyo) 49:691-697.

Kedzierski W, Moghrabi WN, Allen AC, Jablonski-Stiemke MM, Azarian SM, Bok D, Travis GH (1996) Three homologs of rds/peripherin in Xenopus laevis photoreceptors that exhibit covalent and non-covalent interactions. J Cell Sci 109:2551-2560.

Kennedy B, Malicki J (2009) What drives cell morphogenesis: a look inside the vertebrate photoreceptor. Dev Dyn 238:2115-2138.

Kerppola TK (2008) Bimolecular fluorescence complementation (BiFC) analysis as a probe of protein interactions in living cells. Annu Rev Biophys 37:465-487.

Kizhatil K, Baker SA, Arshavsky VY, Bennett V (2009) Ankyrin-G promotes cyclic nucleotide-gated channel transport to rod photoreceptor sensory cilia. Science 323:1614-1617.

Knox BE, Schlueter C, Sanger BM, Green CB, Besharse JC (1998) Transgene expression in Xenopus rods. FEBS Lett 423:117-121.

Körschen HG, Beyermann M, Müller F, Heck M, Vantler M, Koch KW, Kellner R, Wolfrum U, Bode C, Hofmann KP, Kaupp UB (1999) Interaction of glutamic-acid-rich proteins with the cGMP signalling pathway in rod photoreceptors. Nature 400:761-766.

Lee ES, Burnside B, Flannery JG (2006) Characterization of peripherin/rds and rom-1 transport in rod photoreceptors of transgenic and knockout animals. Invest Ophthalmol Vis Sci 47:2150-2160.

Loewen CJ, Molday RS (2000) Disulfide-mediated oligomerization of Peripherin/Rds and Rom-1 in photoreceptor disk membranes. Implications for photoreceptor outer segment morphogenesis and degeneration. J Biol Chem 275:5370-5378.

Loewen CJ, Moritz OL, Tam BM, Papermaster DS, Molday RS (2003) The role of subunit assembly in peripherin-2 targeting to rod photoreceptor disk membranes and retinitis pigmentosa. Mol Biol Cell 14:3400-3413.

Magliery TJ, Wilson CG, Pan W, Mishler D, Ghosh I, Hamilton AD, Regan L (2005) Detecting protein-protein interactions with a green fluorescent protein fragment reassembly trap: scope and mechanism. J Am Chem Soc 127:146-157.

Magupalli VG, Schwarz K, Alpadi K, Natarajan S, Seigel GM, Schmitz F (2008) Multiple RIBEYE-RIBEYE interactions create a dynamic scaffold for the formation of synaptic ribbons. J Neurosci 28:7954-7967.

Michnick SW, Ear PH, Landry C, Malleshaiah MK, Messier V (2010) A toolkit of protein-fragment complementation assays for studying and dissecting large-scale and dynamic protein-protein interactions in living cells. Methods Enzymol 470:335-368.

Molday RS, Hicks D, Molday L (1987) Peripherin. A rim-specific membrane protein of rod outer segment discs. Invest Ophthalmol Vis Sci 28:50-61.

Moritz OL, Tam BM, Knox BE, Papermaster DS (1999) Fluorescent photoreceptors of transgenic Xenopus laevis imaged in vivo by two microscopy techniques. Invest Ophthalmol Vis Sci 40:3276-3280.

Moritz OL, Tam BM, Papermaster DS, Nakayama T (2001) A functional rhodopsin-green fluorescent protein fusion protein localizes correctly in transgenic Xenopus laevis retinal rods and is expressed in a timedependent pattern. J Biol Chem 276:28242-28251.

Moritz OL, Biddle KE, Tam BM (2002) Selection of transgenic Xenopus laevis using antibiotic resistance. Transgenic Res 11:315-319.

Nagai T, Ibata K, Park ES, Kubota M, Mikoshiba K, Miyawaki A (2002) A variant of yellow fluorescent protein with fast and efficient maturation for cell-biological applications. Nat Biotechnol 20:87-90.

Nickell S, Park PS, Baumeister W, Palczewski K (2007) Three-dimensional architecture of murine rod outer segments determined by cryoelectron tomography. J Cell Biol 177:917-925.

Nyfeler B, Michnick SW, Hauri HP (2005) Capturing protein interactions in the secretory pathway of living cells. Proc Natl Acad Sci U S A 102:6350-6355. 
Pentia DC, Hosier S, Cote RH (2006) The glutamic acid-rich protein-2 (GARP2) is a high-affinity rod photoreceptor phosphodiesterase (PDE6) binding protein that modulates its catalytic properties. J Biol Chem 281:5500-5505.

Poetsch A, Molday LL, Molday RS (2001) The cGMP-gated channel and related glutamic acid-rich proteins interact with peripherin- 2 at the rim region of rod photoreceptor disc membranes. J Biol Chem 276:48009-48016.

Ramamurthy V, Cayouette M (2009) Development and disease of the photoreceptor cilium. Clin Genet 76:137-145.

Regus-Leidig H, tom Dieck S., Specht D, Meyer L, Brandstätter JH (2009) Early steps in the assembly of photoreceptor ribbon synapses in the mouse retina: the involvement of precursor spheres. J Comp Neurol 512:814-824.

Ritter LM, Boesze-Battaglia K, Tam BM, Moritz OL, Khattree N, Chen SC, Goldberg AF (2004) Uncoupling of photoreceptor peripherin/rds fusogenic activity from biosynthesis, subunit assembly, and targeting: a potential mechanism for pathogenic effects. J Biol Chem 279:39958-39967.

Ritter LM, Arakawa T, Goldberg AFX (2005) Predicted and measured disorder in peripherin/rds, a retinal tetraspanin. Protein Pept Lett 12:677-686.

Roof DJ, Heuser JE (1982) Surfaces of rod photoreceptor disk membranes: integral membrane components. J Cell Biol 95:487-500.

Rothbauer U, Zolghadr K, Muyldermans S, Schepers A, Cardoso MC, Leonhardt H (2008) A versatile nanotrap for biochemical and functional studies with fluorescent fusion proteins. Mol Cell Proteomics 7:282-289.

Schmitz F, Königstorfer A, Südhof TC (2000) RIBEYE, a component of syn- aptic ribbons: a protein's journey through evolution provides insight into synaptic ribbon function. Neuron 28:857-872.

Sung CH, Chuang JZ (2010) The cell biology of vision. J Cell Biol 190:953-963.

Tam BM, Moritz OL, Papermaster DS (2004) The C terminus of peripherin/ rds participates in rod outer segment targeting and alignment of disk incisures. Mol Biol Cell 15:2027-2037.

Tam BM, Xie G, Oprian DD, Moritz OL (2006) Mislocalized rhodopsin does not require activation to cause retinal degeneration and neurite outgrowth in Xenopus laevis. J Neurosci 26:203-209.

Travis GH, Groshan KR, Lloyd M, Bok D (1992) Complete rescue of photoreceptor dysplasia and degeneration in transgenic retinal degeneration slow (rds) mice. Neuron 9:113-119.

Zacharias DA, Violin JD, Newton AC, Tsien RY (2002) Partitioning of lipidmodified monomeric GFPs into membrane microdomains of live cells. Science 296:913-916.

Zhang Y, Molday LL, Molday RS, Sarfare SS, Woodruff ML, Fain GL, Kraft TW, Pittler SJ (2009) Knockout of GARPs and the beta-subunit of the rod cGMP-gated channel disrupts disk morphogenesis and rod outer segment structural integrity. J Cell Sci 122:1192-1200.

Zheng J, Trudeau MC, Zagotta WN (2002) Rod cyclic nucleotide-gated channels have a stoichiometry of three CNGA1 subunits and one CNGB1 subunit. Neuron 36:891-896.

Zhong H, Molday LL, Molday RS, Yau KW (2002) The heteromeric cyclic nucleotide-gated channel adopts a 3A:1B stoichiometry. Nature 420:193198. 